\title{
Insulin enhances gene expression of Midnolin, a novel genetic risk factor for Parkinson's disease, via ERK, PI3-kinase and multiple transcription factors in SH-SY5Y cells
}

\author{
Naoki Sagehashi ${ }^{1}$, Yutaro Obara ${ }^{1, *}$, Ohki Maruyama ${ }^{1}$, \\ Tadashi Nakagawa ${ }^{2}$, Toru Hosoi ${ }^{2}$, Kuniaki Ishii ${ }^{1}$ \\ ${ }^{1}$ Department of Pharmacology, Yamagata University School of Medicine, \\ Iida-Nishi 2-2-2, Yamagata 990-9585, Japan \\ ${ }^{2}$ Department of Clinical Pharmacology, Faculty of Pharmaceutical Sciences,
}

Sanyo-Onoda City University, Daigaku-Dori 1-1-1, Sanyo Onoda, 756-0884, Japan. 
a) Running title: Insulin regulates gene expression of Midnolin.

b) Correspondence should be addressed to: Yutaro Obara, Ph.D.

Department of Pharmacology, Yamagata University School of Medicine, Iida-Nishi 2-2-2, Yamagata 990-9585, Japan.

Phone: $\quad+81-23-628-5233 ; \quad$ FAX: $\quad+81-23-628-5235 ; \quad$ E-mail: obaray@med.id.yamagata-u.ac.jp

c) Text: 30 pages.

Table: 0

Figures: 9

References: 46

Abstract: 247 words

Introduction: 620 words

Discussion: 1310 words

Supplementary figure: 8

Supplementary Tables: 4

\section{d) Abbreviations:}

AP-1, activator protein 1; ATF, activating transcription factor; ATRA, all-trans retinoic acid; BDNF, brain-derived neurotrophic factor; ChIP, chromatin immunoprecipitation; CREB, cAMP response element-binding protein; EGF, epidermal growth factor; ERK, extracellular-signal regulated kinase; GAPDH, glyceraldehyde-3-phosphate dehydrogenase; GIGYF2, Grb10-interacting GYF protein 2; IGF, insulin-like growth factor; MIDN, midnolin; NGF, nerve growth factor; ODN, oligodeoxynucleotide; PC12, pheochromocytoma; PD, Parkinson's disease; RT-qPCR, reverse transcription-quantitative polymerase chain reaction; TBST, Tris-buffered saline containing $0.1 \%$ tween-20; TFAP2, transcription factor AP-2: TSS, transcription start site. 
e) Recommended section: Cellular and Molecular 


\begin{abstract}
Parkinson's disease (PD) is the second most common neurodegenerative disease. Although many monogenic variants have been identified that cause familial PD, most cases are sporadic and the mechanisms of sporadic PD onset remain unclear. We previously identified Midnolin $(M I D N)$ as a novel genetic risk factor for PD in Japanese population. MIDN copy number loss was strongly associated with sporadic PD, which was replicated in British population. Furthermore, suppression of MIDN expression in rat PC12 cells inhibits neurite outgrowth and expression of Parkin ubiquitin ligase. However, the detailed molecular mechanisms of MIDN expression are unknown. We, therefore, investigated the molecular mechanism of MIDN expression in human neuroblastoma SH-SY5Y cells. We found that MIDN expression was promoted by insulin via extracellular-signal regulated kinase (ERK)1/2 and PI3-kinase-dependent pathways. In addition, MIDN promoter activity was enhanced by mutations at transcription factor AP-2 consensus sequences and reduced by mutations at cAMP response element-binding protein (CREB) and activator protein 1 (AP-1) consensus sequences. The dominant-negative CREB mutant did not block MIDN promoter activity, but both the pharmacological inhibitor and decoy oligodeoxynucleotide for AP-1 significantly blocked its activity. Additionally, DNA binding of c-FOS and c-JUN to the AP-1 consensus sequence in the MIDN promoter was enhanced by insulin as determined by chromatin immunoprecipitation, which suggested that AP-1 positively regulated MIDN expression. Taken together, this study reveals molecular mechanisms of $M I D N$ gene expression induced by insulin in neuronal cells, and drugs which promote $M I D N$ expression may have potential to be a novel medicine for PD.
\end{abstract}

\title{
Significance Statement:
}

We demonstrated that insulin promotes $M I D N$ expression via ERK1/2 and PI3-kinase pathways. Furthermore, we identified the important region of the $M I D N$ promoter and showed that transcription factors, including AP-1, positively regulate MIDN expression, whereas TFAP2 
negatively regulates basal and insulin-induced MIDN expression. We believe that our observations are important and that they contribute to the development of novel drugs to treat Parkinson's disease.

Keywords: Midnolin (MIDN), Parkinson's disease, extracellular-signal regulated kinase (ERK), PI3-kinase, SH-SY5Y cells, insulin, AP-1, TFAP (AP-2) 


\section{Introduction}

Parkinson's disease (PD) is the second most common neurodegenerative disease after Alzheimer's disease. PD prevalence increases with age and it affects more than $1 \%$ of the population over the age of 60 (Lill, 2016). Typical symptoms include resting tremor, bradykinesia, rigidity, and postural instability, and loss of dopaminergic neurons projecting from the substantia nigra in the midbrain to the striatum is pathologically observed. Approximately $10 \%$ of PD cases are familial and many monogenic variants and genetic risk factors have been identified, including SNCA, PRKN, LRRK2, and GBA (Lill, 2016; Scott et al., 2017; Billingsley et al., 2018; Smolders and Van Broeckhoven, 2020). The remaining cases are sporadic and it is assumed that diverse genetic, epigenetic and environmental factors interact in a complex manner to affect disease risk and progression; however, the mechanisms of sporadic PD onset remain unclear.

Midbrain nucleolar protein (Midnolin or MIDN) was discovered in embryonic stem cells by a gene trap method in 2000 (Tsukahara et al., 2000). Midn was named after its specific expression pattern in the midbrain of embryonic (E)12.5 mouse embryos and the intracellular localization of MIDN in the nucleus and nucleolus. A ubiquitin-like domain and a nucleolar localizing sequence are adjacent to the amino and carboxy termini, respectively (Tsukahara et al., 2000). Although MIDN is abundant in the midbrain at early developmental stages, in the adult mouse it is also widely observed in other organs, including heart, spleen, lung, liver, skeletal muscles, kidney, and testis (Tsukahara et al., 2000). The physiological roles of MIDN were unclear for a long time, but in 2013 its ubiquitin-like domain was shown to interact with glucokinase (Hofmeister-Brix et al., 2013). MIDN inhibits glucokinase activity in vitro and glucose-induced insulin secretion from MIN6 cells. Meanwhile, exome analysis of Caucasian girls with autism spectrum disorder revealed many potential genetic variants, one of which was in MIDN (Butler et al., 2015), while array-based analyses showed duplications in 19p13.3, a region including $M I D N$ and other genes that is associated with male infertility (Singh et al., 
2019).

Molecular epidemiological analyses show MIDN to be a novel genetic risk factor for sporadic PD. MIDN copy number loss (deletion) was significantly associated with sporadic PD in a Japanese cohort and this association was replicated in a large-scale British cohort (Obara et al., 2017; Obara et al., 2019). In Yamagata prefecture in northeast Japan, MIDN loss was observed in $10.5 \%$ of patients with sporadic PD whereas MIDN loss was not observed at all in healthy people. In Britain, MIDN loss was similarly observed in $6.55 \%$ of patients with sporadic PD and in $1.64 \%$ of a general population. This frequency $(6.55 \%-10.5 \%)$ is large compared with those of other causal variants, which are usually very small $(<0.5 \%)$. In rat pheochromocytoma (PC12 cells), MIDN expression was enhanced by nerve growth factor (NGF). In addition, NGF-induced neurite outgrowth and expression of Parkin ubiquitin ligase were substantially inhibited by suppression of $M I D N$ expression using genome-editing or RNA interference approaches (Obara et al., 2017; Obara and Ishii, 2018). Although typical DNA-binding or transcription-activating domains have not been identified in the MIDN protein, MIDN affects the transcription levels of a number of genes, including PD-related genes (Obara and Ishii, 2018), indicating that MIDN functions as a transcription modulator. Thus, we believe that MIDN loss is associated with PD although this is controversial (Billingsley et al., 2020; Obara et al., 2020).

$M I D N$ expression in response to NGF is accompanied by the activation of extracellular signal-regulated kinase (ERK) 1/2 and ERK5 in PC12 cells (Obara et al., 2017). However, the detailed molecular mechanisms, particularly the cis-elements and transcription factors responsible for $M I D N$ expression, are unknown. In this study, we therefore investigated the molecular mechanism of MIDN expression in human neuroblastoma SH-SY5Y cells.

\section{Materials and Methods}

\section{Materials}


Recombinant human insulin, all-trans retinoic acid and wortmannin were purchased from Wako Pure Chemicals (Osaka, Japan). Brain-derived neurotrophic factor (BDNF) was purchased from Sigma-Aldrich (St. Louis, MO). Luciferin was purchased from AAT Bioquest (Sunnyvale, CA). SR11302 was purchased from Cayman Chemical (Ann Arbor, MI). U0126, primary antibodies against phospho-Akt (S473) (\#9271), phospho-ERK1/2 (T202/Y204) (\#9101), glyceraldehyde-3-phosphate dehydrogenase (GAPDH) (\#3683), transcription factor AP-2 $\beta$ (TFAP2B) (\#2509), phospho-cAMP response element-binding protein (CREB) (S133) (\#9198), CREB (\#9197) and c-FOS (\#2250), and horseradish peroxidase-conjugated secondary antibody against rabbit IgG (\#7074), were purchased from Cell Signaling Technology (Beverly, MA). Anti-ERK2 antibody (\#sc-154) was purchased from Santa Cruz Biotechnology (Santa Cruz, CA). A synthetic double-stranded decoy oligodeoxynucleotide (ODN) was obtained from Fasmac (Atsugi, Japan). The decoy ODN was generated by annealing equimolar amounts of single-stranded sense and antisense phosphorothioate-modified ODNs that contained an AP-1-binding sequence (Moriyama et al., 2008). A scrambled double-stranded ODN was also generated and used as a control for the AP-1 decoy ODN. The phosphorothioate ODN used in this study was as follows: scrambled ODN (5'-TGT CTC TCT GAT GTC-3' and 5'-GAC ATC AGA GAG ACA-3') and decoy ODN for AP-1 (5'-TGT CTG ACT CAT GTC-3' and 5'- GAC ATG AGT CAG ACA -3') (AP-1 consensus sequences are underlined).

\section{Cell culture}

Human neuroblastoma cells (SH-SY5Y cells) were kindly provided by Dr. Takeo Kato (Yamagata University, Japan) and grown in Dulbecco's modified Eagle's medium supplemented with $10 \%$ foetal bovine serum, penicillin (50 units $/ \mathrm{ml})$ and streptomycin (50 $\mu \mathrm{g} / \mathrm{ml}$ ) in a $5 \% \mathrm{CO}_{2}$ incubator at $37^{\circ} \mathrm{C}$. Differentiation of the cells was induced by adding all-trans retinoic acid $(10 \mu \mathrm{M})$ and incubating for 5 days as described above. For measurement of gene expression and protein phosphorylation levels, cells were incubated in serum-free 
medium before insulin and other drug stimulation.

\section{DNA constructs}

The human MIDN promoter (-600 bp +125 bp) was amplified from genomic DNA of SH-SY5Y cells using a primer set (5'-CCC GCT AGC GCA TCC CCT CAC CAC ACT CCC-3'and 5'-CCC CTC GAG CCC CCT CCA CAC TCA CCG-3') and PrimeStar MAX (Takara, Tokyo, Japan), and inserted between the NheI and XhoI sites of the pGL3-basic luciferase vector (Promega, Madison, WI). Deletion or variations were created by in vitro mutagenesis reactions using PrimeStar MAX. DNA plasmids encoding TFAP2B or its dominant-negative mutant (R225C) were kindly provided by Dr. Satoshi Maegawa (Shiga University of Medical Science, Japan) (Fuke et al., 2010). A plasmid encoding $\beta$-actin promoter-driven $\beta$-galactosidase was a kind gift from Dr. Philip Stork (Vollum Institute, Oregon Health Sciences University, OR). Plasmids that encoded $C R E B$ or its dominant-negative mutant (S133A) were a kind gift from Dr. Takeo Saneyoshi (Kyoto University, Japan).

\section{Western blotting}

Cells were lysed in Laemmli buffer and proteins were separated on $11 \%$ polyacrylamide gels by electrophoresis. Then, the proteins were transferred to polyvinylidene difluoride membranes (GE healthcare, Buckinghamshire, UK) using a semi-dry method. After blocking membranes with 5\% skimmed milk, they were incubated with primary antibodies (1:1000 dilution). The membranes were washed three times and incubated with secondary antibody (1:5000 dilution). After rinsing the membranes, they were developed using an enhanced chemiluminescence kit (PerkinElmer, Waltham, MA or GE healthcare), and visualized with a ChemiDoc XRS imaging system (BioRad, Hercules, CA). The relative band intensities were analysed using Image-J densitometry software (National Institute of Health, Bethesda, MD). The sample number for Western blotting was three for all cases. Quantitative data are shown in supplementary figures. 


\section{Luciferase assay}

SH-SY5Y cells were seeded into 24 -well plates at $1 \times 10^{5}$ cells/well. Plasmids encoding the MIDN promoter linked to the firefly luciferase and $\beta$-actin-driven $\beta$-galactosidase genes, were co-transfected into cells using Lipofectamine 2000 (Invitrogen, Grand Island, NY). After culture for 2 days, the cells were incubated in the presence or absence of insulin $(1 \mu \mathrm{M})$ overnight. The cells were lysed and luciferase activity was measured using a GloMax20/20 luminometer (Promega) as described previously (Honda et al., 2015). As an internal control, $\beta$-actin promoter-driven $\beta$-galactosidase activity was measured to normalize for transfection efficiency as described previously (Honda et al., 2015).

\section{Reverse transcription-quantitative polymerase chain reaction (RT-qPCR)}

Total RNA from SH-SY5Y cells was extracted using TriPure isolation reagent (Roche, Indianapolis, IN) according to the manufacturer's protocol. The RNA was then reverse transcribed using an RT-PCR kit (Toyobo, Osaka, Japan), and real-time PCR was performed using FastStart Essential DNA Green Master for real-time PCR and a LightCycler Nano thermal cycler (Roche), as described previously (Kashino et al., 2018). The PCR primers used were as follows: MIDN (5'-GAG CAG ATG GAC TGC TCC CC-3' and 5'-ACA AAG CTC TCG ATG ACG GC-3'), c-FOS (5'-CAG ACT ACG AGG CGT CAT CC-3' and 5'-AGT TGG TCT GTC TCC GCT TG-3'), and GAPDH (5'-ACC ACA GTC CAT GCC ATC AC-3' and 5'-TCC ACC ACC CTG TTG CTG TA-3'). PCR products were quantified and normalized to the GAPDH control before presentation as a fold change.

\section{Chromatin immunoprecipitation (ChIP) analysis}

ChIP assays were performed as described previously (Nakagawa et al., 2020) with some modifications. Briefly, ten million SH-SY5Y cells were fixed and centrifuged. The cell pellets 
were suspended in nuclear extraction buffer, and centrifuged again. The resulting pellets were suspended in Buf NUC solution, mixed with $\mathrm{CaCl}_{2}$, and digested with micrococcal nuclease (New England Biolabs, M0247S). After the addition of $2 \mathrm{x}$ sonication buffer to stop the reaction, the sample was centrifuged, and the supernatants were incubated with $6 \mu \mathrm{g}$ antibodies [IgG control (MBL, PM035), anti-c-JUN (Cell Signaling Technology, 9165) or anti-c-FOS (Cell Signaling Technology, 2250) antibody] conjugated to magnetic beads (Thermo Fisher, DB10004). Bead-bound proteins were washed with buffer A, buffer B, buffer C, TE buffer, and the samples were then eluted by $\mathrm{RNase} \mathrm{A}$, proteinase $\mathrm{K}$, and $\mathrm{NaCl}$. After incubation with proteinase $\mathrm{K}$ again, DNA was purified with AMpure XP beads, eluted with TE buffer, and subjected to real-time PCR analysis with the use of Fast SYBR ${ }^{\mathrm{TM}}$ Green Master Mix (Thermo Fisher, 4385612). The primers for amplification of the MIDN promoter were 5'-TGG CTC GGG GCA TTC AAG-3' and 5'-TTT ATC CGC GCC GCC TTC-3' and those of MIDN intron 1 were 5'-CGG CTT TTC CCG GAC GAA-3' and 5'-ACG GGT CTG GTA CCC CTC-3'.

\section{Statistics}

Data are expressed as the mean \pm S.E.M, and the statistical significance of the differences was analysed using Student's T-test (Fig. 8E) or one-way ANOVA with post hoc Tukey's test (Figs. 2C, 3A, 4A, 4B, 8A, 8C, 8D, S4, S5, S7 and S8) or Dunnett's test (Figs. 1A, 1B, 2A, 5B, 5C, 6A, 7B, S1, S2, S3, and S6) for multiple comparisons. StatView software (ver5.0) (SAS institute Inc., Tokyo, Japan) was used for statistical analysis.

\section{Results}

Insulin enhances MIDN gene expression in SH-SY5Y cells. Human neuroblastoma SH-SY5Y cells were incubated with insulin $(1 \mu \mathrm{M})$ or BDNF (30 or $50 \mathrm{ng} / \mathrm{ml})$ for $2 \mathrm{~h}$, and MIDN expression levels were examined by RT-qPCR (Fig. 1A). MIDN expression was significantly enhanced by insulin, but not by BDNF. Next, we subcloned the human MIDN promoter region 
either side of the transcription start site (TSS) $(-650 \sim+125 \mathrm{bp})$ into pGL3, which encodes a promoter-less firefly luciferase. In SH-SY5Y cells transfected with this DNA construct, the luciferase gene is efficiently expressed when the MIDN promoter is activated by a stimulant. We measured the human $M I D N$ promoter activity in response to insulin $(1 \mathrm{nM}$ to $1 \mu \mathrm{M})$ and found it to be significantly increased in a concentration-dependent manner (Fig. 1B). To examine the signalling pathways activated by insulin, phosphorylation levels of ERK1/2 and Akt were examined as indices of activation of ERK1/2 and PI3-kinase, respectively. Insulin promoted phosphorylation of both ERK1/2 and Akt, but BDNF failed to cause the phosphorylation of Akt or ERK1/2 (Figs. 1C and 1D and Supplementary Figs. S1 and S2). SH-SY5Y cells express the BDNF TrkB receptor and acquire sensitivity to BDNF during neuronal differentiation by retinoic acid (Sakane and Shidoji, 2011; Shiohira et al., 2012); therefore, the cells were incubated with retinoic acid $(10 \mu \mathrm{M})$ for 5 days and were then stimulated with BDNF $(50 \mathrm{ng} / \mathrm{ml})$ or insulin $(1 \mu \mathrm{M})$ for 1 or $2 \mathrm{~h}$. BDNF, in addition to insulin, significantly enhanced $M I D N$ expression in these differentiated cells (Fig. 2A). BDNF (30 or 50 $\mathrm{ng} / \mathrm{ml}$ ) treatment for 5 min also caused phosphorylation of both ERK1/2 and Akt (Fig. 2B and Supplementary Fig. S3), confirming that the TrkB receptor tyrosine kinase was activated by BDNF in the differentiated cells. When MIDN expression was compared between undifferentiated and differentiated cells under the same conditions, MIDN expression in differentiated cells was significantly higher than that in undifferentiated cells, although insulin increased $M I D N$ expression levels to a similar extent regardless of differentiation states (Fig. 2C). Phosphorylation of ERK1/2 and Akt was related to MIDN expression levels (Fig. 2D and Supplementary Fig. S4). However, because the effect of insulin was more potent than that of BDNF and obvious in both undifferentiated and differentiated cells, we focused on insulin signalling that led to MIDN expression in undifferentiated cells. SH-SY5Y cells were pre-incubated in the presence or absence of a MEK inhibitor, U0126 (30 $\mu \mathrm{M})$, or a PI3-kinase inhibitor, wortmannin $(500 \mathrm{nM})$, for $30 \mathrm{~min}$, then stimulated with insulin $(1 \mu \mathrm{M})$ for $2 \mathrm{~h}$. 
RT-qPCR analysis showed that insulin increased MIDN expression, which was largely blocked by U0126 or wortmannin and was completely suppressed by the combination of U0126 and wortmannin (Fig. 3A). Inhibition of PI3-kinase and ERK1/2 by these inhibitors was confirmed by Western blotting (Fig. 3B and Supplementary Fig. S5). These data indicate that insulin promotes $M I D N$ expression accompanied by the activation of ERK1/2 and PI3-kinase in SH-SY5Y cells.

\section{Transcription factors, including TFAP2 and AP-1, regulate human MIDN promoter activity}

in SH-SY5Y cells. To examine the insulin signalling pathway involved in increased MIDN expression in more detail, we measured MIDN promoter activity using reporter plasmids encoding various length of the $M I D N$ promoter $(-600,-450,-300,-150,-100$ and -50 bp to +125 bp). We found a region that negatively regulates promoter activity between $-150 \mathrm{bp}$ and $-100 \mathrm{bp}$ and a region that positively regulates its activity between -100 and -50 bp (Fig. 4A). This was also observed after insulin stimulation (Fig. 4B), suggesting that multiple transcription factors are involved in $M I D N$ expression.

In silico analysis of the JASPAR2020 database (Fornes et al., 2020), identified TFAP2 consensus sequences between -121 bp and -99 bp upstream of the TSS (5'-AGC CGT CAA GGC GCC CCA GGG CC-3'). The highest TFAP2 family member binding affinity scores were 12.9646 for TFAP2A, 12.2031 for TFAP2B and 12.6803 for TFAP2C, indicating that the sequence in this region of the MIDN promoter is highly similar to the consensus sequence for all TFAP2 isoforms (Table S1). We also discovered the consensus sequence for activator protein 1 (AP-1) and for the CREB/Activating transcription factor (ATF) family in the promoter region between -71 bp and -57 bp (5'-GTC TGC GTC ACC GCC-3') (Table S2-S4). The highest scores for binding affinity with these transcription factors were 10.5189 for FOSL1/JUN, 10.9754 for ATF1 and 11.1485 for CREB1. Furthermore, there is a region between these sites putatively recognized by various other transcription factors including KLF, SP, and EGR family 
members. To identify the specific cis-elements involved in MIDN expression, the putative binding sequences for these transcription factors were mutated as indicated in Fig. 5A. Both basal and insulin $(1 \mu \mathrm{M})$-stimulated $M I D N$ promoter activity was significantly enhanced by mutations at TFAP2 consensus sites (Mut 1 and 2) and also by mutations 3 and 4 (Fig. 5B). In contrast, basal and insulin $(1 \mu \mathrm{M})$-stimulated $M I D N$ promoter activity was significantly reduced by the mutation at the CREB/ATF family and AP-1 family consensus sites (Mut 5) (Fig. 5C).

Because TFAP2 was suggested to be involved in regulation of MIDN expression, wild-type TFAP2B and its dominant-negative mutant (R225C) were overexpressed in SH-SY5Y cells and MIDN promoter activity $(-150 \sim+125)$ was measured. This dominant-negative mutant lacks DNA-binding ability (Fuke et al., 2010). Although overexpression of TFAP2 did not reduce the promoter activity, its dominant-negative mutant promoted promoter activity (Fig. 6A), indicating that TFAP2B negatively regulates $M I D N$ expression. Overexpression of TFAP2B and TFAP2B R225C was confirmed by Western blotting (Fig. 6B and Supplementary Fig. S6).

To investigate the activity and involvement of CREB in MIDN expression, phosphorylation levels of CREB and ATF1 were also examined by Western blotting as an index of activation. This phospho-specific CREB antibody used also recognizes phospho-ATF1 (S63), but only phosphorylation of CREB was enhanced by insulin $(1 \mu \mathrm{M})$; there was no conclusive phosphorylated ATF1 band (Fig. 7A). Densitometric analysis showed that U0126 (30 $\mu \mathrm{M})$ blocked this CREB phosphorylation by $50.0 \%(\mathrm{n}=3, p<0.05)$, while wortmannin $(500 \mathrm{nM})$ only reduced it by $17.3 \%(\mathrm{n}=3, p>0.05)$, indicating that insulin activates CREB, which was accompanied mainly by ERK1/2 signalling (Supplementary Fig. S7). Additionally, a dominant-negative mutant of CREB S133A, which lacked its phosphorylation sites at Ser133, was overexpressed in cells stimulated with insulin $(1 \mu \mathrm{M})$. However, the $M I D N$ promoter was not inhibited by the CREB S133A mutant (Fig. 7B).

Next, to investigate the activity and involvement of AP-1 in MIDN expression, mRNA and protein expression levels of c-FOS were measured by RT-qPCR and Western blotting, 
respectively, as an index of AP-1 transcriptional activity. Insulin $(1 \mu \mathrm{M})$ significantly enhanced c-FOS mRNA expression, which was significantly reversed by U0126 $(30 \mu \mathrm{M})$, but not wortmannin $(500 \mathrm{nM})$, which suggested that the ERK1/2 pathway was involved in $c-F O S$ induction (Fig. 8A). c-FOS protein was also induced by insulin treatment $(1 \mu \mathrm{M})$ for $2 \mathrm{~h}$, which was completely inhibited by U0126 $(30 \mu \mathrm{M})$ and partially, but significantly, inhibited by wortmannin (500 nM) (Fig. 8B and Supplementary Fig. S8). To examine the involvement of AP-1 in MIDN expression, the decoy ODN ( $2 \mu \mathrm{g} /$ well) for AP-1 was cotransfected with reporter genes into cells that were stimulated with insulin $(1 \mu \mathrm{M})$. As a result, the decoy ODN for AP-1 completely inhibited the insulin $(1 \mu \mathrm{M})$-induced $M I D N$ promoter activation (Fig. 8C). To confirm the roles of AP-1, we used a pharmacological inhibitor, SR11302, which is a synthetic retinoid derivative that inhibits AP-1 activity without activating retinoid response elements (Li et al., 1997). SR11302 (30 $\mu \mathrm{M})$ significantly inhibited the $M I D N$ promoter activation induced by insulin (Fig. 8D). Finally, a ChIP assay was performed using c-FOS and c-JUN antibodies to confirm that AP-1 bound to its consensus sequence (-71 to $-57 \mathrm{bp}$ ) in the $M I D N$ promoter and identify the AP-1 isoforms involved in this case (Fig. 8E). As expected, insulin (1 $\mu \mathrm{M})$ significantly promoted DNA binding of both c-FOS and c-JUN to its predicted corresponding sequence, but not to intron 1 ( +840 to $+969 \mathrm{bp}$ ) as a negative control sequence. Taken together, these results suggest that $\mathrm{AP}-1$ rather than $\mathrm{CREB}$ is involved in insulin-induced MIDN expression, although CREB is also activated by insulin in an ERK1/2-dependent manner.

\section{Discussion}

In this study, we found that insulin promoted MIDN expression in human neuroblastoma cells via ERK1/2 and PI3-kinase-dependent pathways. In addition, the MIDN promoter was regulated in multiple ways by various transcription factors. AP-1 enhance whereas TFAP2 suppresses MIDN expression. These signalling pathways are depicted in Fig. 9. 
Although insulin generally modulates peripheral glucose metabolism, it is efficiently transported into the brain through its specific mechanism to cross the blood brain barrier (Ghasemi et al., 2013; Gray and Barrett, 2018). Insulin transcripts have been detected in GABAergic neurogliaform cells in the cortex, which act in cortical microcircuits (Molnar et al., 2014), and in the rat hippocampus (Nemoto et al., 2014). Furthermore, insulin-like growth factor (IGF) $1 / 2$, which interacts with insulin receptors, is biosynthesized in glial cells. Insulin receptor is abundantly expressed in the central nervous system, especially in post-synaptic neurons (Wada et al., 2005), which suggests that central insulin regulates behaviour and cognitive functions other than glucose homeostasis (Zhao and Alkon, 2001). Moreover, dysfunction in insulin signalling is associated with neurodegenerative diseases (Moroo et al., 1994; Craft and Watson, 2004; Trejo et al., 2004). Remarkably, Grb10-interacting GYF protein 2 (GIGYF2) interacts with insulin and IGF receptors through Grb10, and mutations in the GIGYF2 gene within the Park11 locus have been associated with PD (Lautier et al., 2008; Blauwendraat et al., 2020). Gigyf2 knockout mice exhibit motor dysfunction and $\alpha$-synuclein-positive plaques, which implies that abnormal insulin signalling is associated with PD (Giovannone et al., 2009).

Although the relationship between PD and diabetes mellitus has been controversial, the shared biological mechanisms and positive clinical and epidemiological association between type2 diabetes and PD are currently an interesting hypothesis (Sánchez-Gómez et al., 2020; 2021). Whereas certain oral anti-diabetic drugs, which include pioglitazone and metformin, have not had a significant benefit in clinical trials, daily intranasal administration of insulin improved motor impairment and had a positive effect on cognitive functions (Novak et al., 2019). Furthermore, exenatide, an agonist of the glucagon-like peptide-1 receptor, exerted a positive effect on practically defined off-medication motor scores in a clinical trial for PD patients, although the effect of exenatide on pathophysiology and long-lasting symptomatic improvement remains unclear (Athauda et al., 2017; 2019). The relevance of PD to diabetes and 
the effectiveness of anti-diabetic drugs on PD should be clarified in both in vitro and in vivo/clinical studies.

We previously showed that $M I D N$ expression was enhanced by NGF, but not by epidermal growth factor (EGF) or basic fibroblast growth factor in PC12 cells (Obara et al., 2017). In addition, the NGF-induced $M I D N$ expression was both ERK1/2 and ERK5-dependent. In this study, insulin enhanced MIDN expression in SH-SY5Y cells accompanied by activation of ERK1/2 and PI3-kinase (Figs. 1 and 3). MIDN expression was also enhanced by BDNF in cells differentiated by retinoic acid and in which TrkB receptor was induced (Sakane and Shidoji, 2011; Shiohira et al., 2012) (Fig. 2). The majority of neurotrophic factors and growth factors activate both ERKs and PI3-kinase in a similar manner through their specific receptor tyrosine kinases. However, there are differences in the intracellular signalling that depend on the growth factors and cell type. For example, NGF causes sustained ERK1/2 activation via the small G-proteins, Ras and Rap1, whereas this activation is only transient and Ras-dependent in case of EGF in PC12 cells (York et al., 1998; Obara et al., 2004). This difference affects cell fate; NGF induces neuronal differentiation and EGF promotes proliferation. The reason why only certain neurotrophic factors or growth factors affect $M I D N$ expression remains unknown, but it is suggested that NGF or insulin-specific signalling pathways in addition to those involving ERKs and PI3-kinase may be responsible for MIDN expression. Because growth/neurotrophic factors, including insulin, BDNF and glial cell-derived neurotrophic factor, have neurotrophic effects and clinical potential for the treatment of PD (Allen et al., 2013; Shaughness et al., 2020), it is important to examine whether they induce $M I D N$ expression, particularly in vivo.

By MIDN promoter analysis, we found that TFAP2 negatively regulated MIDN expression. Deleting or mutating the TFAP2 consensus sequence between -121 bp and -99 bp upstream of the TSS (5'-AGC CGT CAA GGC GCC CCA GGG CC-3') increased promoter activity (Figs. 4 and 5, Table S1). In addition, the promoter activity was promoted by overexpression of a dominant-negative TFAP2B mutant that lacks DNA binding activity (Fig. 6A). However, 
overexpression of wild-type TFAP2B did not cause a significant reduction of promoter activity. SH-SY5Y cells express TFAP2B (Fig. 6B), which may be sufficient for negative regulation of the MIDN promoter. Generally, TFAP2 forms homo- or hetero-dimers with other TFAP2 family members, and functions as both an activator and repressor of gene transcription. TFAP2B mediates retinoic acid-induced noradrenergic neuronal differentiation in neuroblastoma, including SH-SY5Y cells (Ikram et al., 2016). In our study, TFAP2 suppressed MIDN gene expression in SH-SY5Y cells, but the physiological significance of this remains unknown. It is necessary to clarify the molecular mechanism by which insulin regulates TFAP2 activity and how TFAP2 inhibits MIDN expression. We discovered that the promoter region between $-71 \mathrm{bp}$ and -57 bp (5'-GTC TGC GTC ACC GCC-3'), which contains consensus binding sequences for AP-1 and the CREB/ATF family (Table S2-S4), was required for MIDN expression. Furthermore, this sequence is conserved among mammals, which suggests universal roles in $M I D N$ expression. We found that AP-1 activity, rather than CREB, was involved in MIDN expression as demonstrated by attenuation of $M I D N$ promoter activity by both a pharmacological inhibitor (SR11302) and decoy ODN for AP-1, whereas the dominant-negative CREB S133A mutant did not decrease its promoter activity (Figs. 7 and 8). Additionally, insulin promoted DNA binding of both c-FOS and c-JUN isoforms to the predicted AP-1 consensus binding sequence (Fig. 8E), which suggested that both AP-1 isoforms are required for MIDN expression. AP-1 activity is regulated at multiple levels. For example, expression of AP-1 components is controlled by mRNA synthesis and stability as ERKs strongly stimulate AP-1 activity via de novo synthesis of c-FOS and c-JUN. Additionally, the DNA-binding ability and transactivating capacity of AP-1 are controlled by post-translational modifications, which include phosphorylation and ubiquitination as JUN N-terminal kinase phosphorylates c-JUN. In our study, insulin actually promoted $c-F O S$ expression at mRNA and protein levels in an ERK1/2-dependent manner (Figs. 8A and 8B) and ERK1/2 was involved in MIDN expression induced by insulin (Fig. 3), indicating that the ERK1/2/AP-1 pathways are essential for MIDN 
expression. Because c-FOS protein levels were partially, but significantly, reduced by a PI3-kinase inhibitor (Fig. 8B and Supplementary Fig S8), AP-1 activity was also regulated by the PI3-kinase pathway via a post-translational modification. Because inhibition of PI3-kinase and ERK1/2 suppressed $M I D N$ expression to similar extents (Fig. 3), the PI3-kinase pathway is also required for $M I D N$ expression although the down-stream signalling pathway is unclear. Both ERK1/2 and PI3-kinase are essential for neuronal differentiation and survival, and targeting these pathways has been proposed as a reasonable approach to suppress various neurodegenerative disorders (Markus et al., 2002; Obara et al., 2004; Rai et al., 2019). MIDN induced through ERK signalling is responsible for neurite outgrowth in PC12 cells (Obara et al., 2017); therefore, MIDN is assumed to be a key regulator in the maintenance of appropriate neuronal functions, and MIDN dysfunction can be a risk factor for the onset and progression of neurodegenerative disorders such as PD. Therefore, drugs that promote the MIDN expression may have potential to be a novel medicine for PD, which may be useful for not only patients who have MIDN copy number loss, but also for those who have the normal copy number.

In summary, we demonstrated that insulin promotes $M I D N$ expression via ERK1/2 and PI3-kinase pathways. Furthermore, we identified the important region of the MIDN promoter and showed that transcription factors, including AP-1, positively regulate MIDN expression, whereas TFAP2 negatively regulates basal and insulin-induced $M I D N$ expression. Identification of MIDN-binding partners and the clarification of MIDN roles in vivo are key future studies.

\section{Acknowledgments}

We thank Dr. Satoshi Maegawa (Shiga University of Medical Science, Japan) and Dr. Takeo Saneyoshi (Kyoto University, Japan) for providing the plasmids encoding TFAP2B and $C R E B$ mutant, respectively. We thank Ryoko Murakami, Yuki Miyano and Dr. Hidenori Sato (Yamagata University School of Medicine, Japan) for GC-rich DNA sequencing. We thank the JASPAR2020 database (http://jaspar.genereg.net) group members who provided the 
transcription factor binding profiles. We thank Jeremy Allen, $\mathrm{PhD}$, from Edanz Group (https://jp.edanz.com/ac) for editing a draft of this manuscript.

\section{Author Contributions}

Participated in research design: Obara, Hosoi, Ishii

Performed experiments: Sagehashi, Maruyama, Nakagawa

Performed data analysis: Sagehashi, Nakagawa

Wrote or contributed to the writing of the manuscript: Obara, Nakagawa, Ishii 


\section{References}

Allen SJ, Watson JJ, Shoemark DK, Barua NU and Patel NK (2013) GDNF, NGF and BDNF as therapeutic options for neurodegeneration. Pharmacol Ther 138:155-175.

Athauda D, Maclagan K, Budnik N, Zampedri L, Hibbert S, Aviles-Olmos I, Chowdhury K, Skene SS, Limousin P and Foltynie T (2019) Post hoc analysis of the Exenatide-PD trial-Factors that predict response. Eur J Neurosci 49:410-421.

Athauda D, Maclagan K, Skene SS, Bajwa-Joseph M, Letchford D, Chowdhury K, Hibbert S, Budnik N, Zampedri L, Dickson J, Li YZ, Aviles-Olmos I, Warner TT, Limousin P, Lees AJ, Greig NH, Tebbs S and Foltynie T (2017) Exenatide once weekly versus placebo in Parkinson's disease: a randomised, double-blind, placebo-controlled trial. Lancet 390:1664-1675.

Billingsley KJ, Bandres-Ciga S, Ding JH, Hernandez D, Gibbs JR and Blauwendraat C (2020) MIDN locus structural variants and Parkinson's Disease risk. Ann Clin Transl Neur 7:602-603.

Billingsley KJ, Bandres-Ciga S, Saez-Atienzar S and Singleton AB (2018) Genetic risk factors in Parkinson's disease. Cell Tissue Res 373:9-20.

Blauwendraat C, Nalls MA and Singleton AB (2020) The genetic architecture of Parkinson's disease. Lancet Neurology 19:170-178.

Butler MG, Rafi SK, Hossain W, Stephan DA and Manzardo AM (2015) Whole exome sequencing in females with autism implicates novel and candidate genes. Int $\mathrm{J} \mathrm{Mol} \mathrm{Sci}$ 16:1312-1335.

Craft S and Watson GS (2004) Insulin and neurodegenerative disease: shared and specific mechanisms. Lancet Neurology 3:169-178.

Fornes O, Castro-Mondragon JA, Khan A, van der Lee R, Zhang X, Richmond PA, Modi BP, Correard S, Gheorghe M, Baranasic D, Santana-Garcia W, Tan G, Cheneby J, Ballester B, Parcy F, Sandelin A, Lenhard B, Wasserman WW and Mathelier A (2020) JASPAR 
2020: update of the open-access database of transcription factor binding profiles. Nucleic Acids Res 48:D87-D92.

Fuke T, Yoshizaki T, Kondo M, Morino K, Obata T, Ugi S, Nishio Y, Maeda S, Kashiwagi A and Maegawa H (2010) Transcription factor AP-2beta inhibits expression and secretion of leptin, an insulin-sensitizing hormone, in 3T3-L1 adipocytes. Int $J$ Obes (Lond) 34:670-678.

Ghasemi R, Haeri A, Dargahi L, Mohamed Z and Ahmadiani A (2013) Insulin in the Brain: Sources, Localization and Functions. Mol Neurobiol 47:145-171.

Giovannone B, Tsiaras WG, de la Monte S, Klysik J, Lautier C, Karashchuk G, Goldwurm S and Smith RJ (2009) GIGYF2 gene disruption in mice results in neurodegeneration and altered insulin-like growth factor signaling. Human Molecular Genetics 18:4629-4639.

Gray SM and Barrett EJ (2018) Insulin transport into the brain. Am J Physiol-Cell Ph 315:C125-C136.

Hofmeister-Brix A, Kollmann K, Langer S, Schultz J, Lenzen S and Baltrusch S (2013) Identification of the ubiquitin-like domain of midnolin as a new glucokinase interaction partner. The Journal of biological chemistry 288:35824-35839.

Honda T, Obara Y, Yamauchi A, Couvillon AD, Mason JJ, Ishii K and Nakahata N (2015) Phosphorylation of ERK5 on Thr732 is associated with ERK5 nuclear localization and ERK5-dependent transcription. PloS one 10:e0117914.

Ikram F, Ackermann S, Kahlert Y, Volland R, Roels F, Engesser A, Hertwig F, Kocak H, Hero B, Dreidax D, Henrich KO, Berthold F, Nurnberg P, Westermann F and Fischer M (2016) Transcription factor activating protein 2 beta (TFAP2B) mediates noradrenergic neuronal differentiation in neuroblastoma. Mol Oncol 10:344-359.

Kashino Y, Obara Y, Okamoto Y, Saneyoshi T, Hayashi Y and Ishii K (2018) ERK5 Phosphorylates K(v)4.2 and Inhibits Inactivation of the A-Type Current in PC12 Cells. International Journal of Molecular Sciences 19. 
Lautier C, Goldwurm S, Durr A, Giovannone B, Tsiaras WG, Pezzoli G, Brice A and Smith RJ (2008) Mutations in the GIGYF2 (TNRC15) gene at the PARK11 locus in familial Parkinson disease. American Journal of Human Genetics 82:822-833.

Li JJ, Westergaard C, Ghosh P and Colburn NH (1997) Inhibitors of both nuclear factor-kappa Beta and activator protein-1 activation block the neoplastic transformation response. Cancer Res 57:3569-3576.

Lill CM (2016) Genetics of Parkinson's disease. Mol Cell Probes 30:386-396.

Markus A, Patel TD and Snider WD (2002) Neurotrophic factors and axonal growth. Curr Opin Neurobiol 12:523-531.

Molnar G, Farago N, Kocsis AK, Rozsa M, Lovas S, Boldog E, Baldi R, Csajbok E, Gardi J, Puskas LG and Tamas G (2014) GABAergic Neurogliaform Cells Represent Local Sources of Insulin in the Cerebral Cortex. Journal of Neuroscience 34:1133-1137.

Moriyama I, Ishihara S, Rumi MAK, Aziz MDM, Mishima Y, Oshima N, Kadota C, Kadowaki Y, Amano Y and Kinoshita Y (2008) Decoy oligodeoxynucleotide targeting activator protein-1 (AP-1) attenuates intestinal inflammation in murine experimental colitis. Lab Invest 88:652-663.

Moroo I, Yamada T, Makino H, Tooyama I, Mcgeer PL, Mcgeer EG and Hirayama K (1994) Loss of Insulin-Receptor Immunoreactivity from the Substantia-Nigra Pars-Compacta Neurons in Parkinsons-Disease. Acta Neuropathol 87:343-348.

Nakagawa T, Hattori S, Nobuta R, Kimura R, Nakagawa M, Matsumoto M, Nagasawa $Y$, Funayama R, Miyakawa T, Inada T, Osumi N, Nakayama KI, Nakayama K (2020) The autism-related protein SETD5 controls neural cell proliferation through epigenetic regulation of rDNA expression. iScience 23:101030.

Nemoto T, Toyoshima-Aoyama F, Yanagita T, Maruta T, Fujita H, Koshida T, Yonaha T, Wada A, Sawaguchi A and Murakami M (2014) New insights concerning insulin synthesis and its secretion in rat hippocampus and cerebral cortex: 
Amyloid-beta(1-42)-induced reduction of proinsulin level via glycogen synthase kinase-3 beta. Cellular signalling 26:253-259.

Novak P, Maldonado DAP and Novak V (2019) Safety and preliminary efficacy of intranasal insulin for cognitive impairment in Parkinson disease and multiple system atrophy: A double-blinded placebo-controlled pilot study. PloS one 14:e0214364.

Obara Y, Imai T, Sato H, Takeda Y, Kato T and Ishii K (2017) Midnolin is a novel regulator of parkin expression and is associated with Parkinson's Disease. Sci Rep 7:5885.

Obara Y and Ishii K (2018) Transcriptome Analysis Reveals That Midnolin Regulates mRNA Expression Levels of Multiple Parkinson's Disease Causative Genes. Biol Pharm Bull 41:20-23.

Obara Y, Labudda K, Dillon TJ and Stork PJ (2004) PKA phosphorylation of Src mediates Rap1 activation in NGF and cAMP signaling in PC12 cells. J Cell Sci 117:6085-6094.

Obara Y, Sato H, Nakayama T, Kato T and Ishii K (2019) Midnolin is a confirmed genetic risk factor for Parkinson's disease. Ann Clin Transl Neur 6:2205-2211.

Obara Y, Sato H, Nakayama T, Kato T and Ishii K (2020) Reply to: MIDN locus structural variants and Parkinson's disease risk. Ann Clin Transl Neur 7:604-605.

Rai SN, Dilnashin H, Birla H, Sen Singh S, Zahra W, Rathore AS, Singh BK and Singh SP (2019) The Role of PI3K/Akt and ERK in Neurodegenerative Disorders. Neurotox Res 35:775-795.

Sakane C and Shidoji Y (2011) Reversible upregulation of tropomyosin-related kinase receptor B by geranylgeranoic acid in human neuroblastoma SH-SY5Y cells. J Neuro-Oncol 104:705-713.

Sánchez-Gómez A, Alcarraz-Vizan G, Fernandez M, Fernandez-Santiago R, Ezquerra M, Camara A, Serrano M, Novials A, Munoz E, Valldeoriola F, Compta Y and Marti MJ (2020) Peripheral insulin and amylin levels in Parkinson's disease. Parkinsonism Relat D 79:91-96. 
Sánchez-Gómez A, Compta Y, Martí MJ (2021) Insulin-releasing or insulin-sensitizing drugs in Parkinson's disease? Choosing a pathway. Parkinsonism Relat D 93:109-110.

Scott L, Dawson VL and Dawson TM (2017) Trumping neurodegeneration: Targeting common pathways regulated by autosomal recessive Parkinson's disease genes. Exp Neurol 298:191-201.

Shaughness M, Acs D, Brabazon F, Hockenbury N and Byrnes KR (2020) Role of Insulin in Neurotrauma and Neurodegeneration: A Review. Front Neurosci-Switz 14.

Shiohira H, Kitaoka A, Enjoji M, Uno T and Nakashima M (2012) Am80 induces neuronal differentiation via increased tropomyosin-related kinase B expression in a human neuroblastoma SH-SY5Y cell line. Biomed Res-Tokyo 33:291-297.

Singh V, Bala R, Chakraborty A, Rajender S, Trivedi S and Singh K (2019) Duplications in 19p13.3 are associated with male infertility. J Assist Reprod Gen 36:2171-2179.

Smolders S and Van Broeckhoven C (2020) Genetic perspective on the synergistic connection between vesicular transport, lysosomal and mitochondrial pathways associated with Parkinson's disease pathogenesis. Acta Neuropathol Com 8:63.

Trejo JL, Carro E, Garcia-Galloway E and Torres-Aleman I (2004) Role of insulin-like growth factor I signaling in neurodegenerative diseases. J Mol Med 82:156-162.

Tsukahara M, Suemori H, Noguchi S, Ji ZS and Tsunoo H (2000) Novel nucleolar protein, midnolin, is expressed in the mesencephalon during mouse development. Gene 254:45-55.

Wada A, Yokoo H, Yanagita T and Kobayashi H (2005) New twist on neuronal insulin receptor signaling in health, disease, and therapeutics. J Pharmacol Sci 99:128-143.

York RD, Yao H, Dillon T, Ellig CL, Eckert SP, McCleskey EW and Stork PJ (1998) Rap1 mediates sustained MAP kinase activation induced by nerve growth factor. Nature 392:622-626.

Zhao WQ and Alkon DL (2001) Role of insulin and insulin receptor in learning and memory. 
Molecular and cellular endocrinology 177:125-134.

\section{Footnotes}

This work was supported in part by Grants-in-Aid from the Japan Society for the Promotion of Science (18K06681 to Y.O), Takeda Science Foundation (Y.O), and Setsuro Fujii Memorial, the Osaka Foundation for Promotion of Fundamental Medical Research (Y.O). The funding sponsors had no role in the design of the study, in the collection, analyses or interpretation of the data, nor in the writing of the manuscript and in the decision to publish the results.

\section{Conflict of interest}

The authors declare that they have no conflicts of interest with the contents of this article.

\section{Material availability}

There is a restriction to share the DNA plasmids (TFAP2 WT and mutants). Please contact Dr. Satoshi Maegawa (Shiga University of Medical Science, Japan) for permission to obtain the DNA plasmids. 


\section{Figure legends}

Figure 1: Insulin promotes MIDN expression in SH-SY5Y cells. (A) SH-SY5Y cells were stimulated with insulin $(1 \mu \mathrm{M})$ or BDNF (30 or $50 \mathrm{ng} / \mathrm{ml}$ ) for $2 \mathrm{~h}$, then expression levels of $M I D N$ were examined by RT-qPCR. Insulin significantly promoted $M I D N$ expression ( $\mathrm{n}=3-9$, $\left.{ }^{*} p<0.05\right)$. (B) SH-SY5Y cells were transfected with MIDN promoter $(-600 \sim+125 \mathrm{bp})$ linked to luciferase in a promoter-less plasmid (pGL3). After stimulation with insulin (1 nM to $1 \mu \mathrm{M})$, $M I D N$ promoter activity was examined by measuring luciferase activity. Insulin significantly promoted MIDN promoter activity $\left(\mathrm{n}=3,{ }^{*} p<0.05\right)$. (C) SH-SY5Y cells were stimulated with insulin $(1 \mu \mathrm{M})$ for 5, 15, and $30 \mathrm{~min}$, then phosphorylation of Akt and ERK1/2 was examined by Western blotting. (D) SH-SY5Y cells were stimulated with insulin $(1 \mu \mathrm{M})$ or BDNF (30 or $50 \mathrm{ng} / \mathrm{ml}$ ) for $5 \mathrm{~min}$, then phosphorylation of Akt and ERK1/2 was examined by Western blotting.

Figure 2: BDNF and insulin promote MIDN expression in differentiated SH-SY5Y cells.

(A) SH-SY5Y cells differentiated by all-trans retinoic acid $(10 \mu \mathrm{M})$ for 5 days were stimulated with insulin $(1 \mu \mathrm{M})$ or BDNF $(50 \mathrm{ng} / \mathrm{ml})$ for 1 or $2 \mathrm{~h}$, then expression levels of MIDN were examined by RT-qPCR. Insulin and BDNF significantly promoted $M I D N$ expression $(\mathrm{n}=3$, $\left.{ }^{*} p<0.05\right)$. (B) Differentiated SH-SY5Y cells were stimulated with insulin $(1 \mu \mathrm{M})$ or BDNF (30 or $50 \mathrm{ng} / \mathrm{ml}$ ) for $5 \mathrm{~min}$, then phosphorylation of Akt and ERK1/2 was examined by Western blotting. (C) SH-SY5Y cells were incubated in the presence or absence of all-trans retinoic acid (ATRA) $(10 \mu \mathrm{M})$ for 5 days and then stimulated with insulin $(1 \mu \mathrm{M})$ for $2 \mathrm{~h}$. Then, expression levels of MIDN were examined by RT-qPCR. MIDN expression in differentiated cells was significantly higher than that in undifferentiated cells $\left(\mathrm{n}=3,{ }^{*} p<0.05\right)$. (D) Undifferentiated and differentiated SH-SY5Y cells were stimulated with insulin $(1 \mu \mathrm{M})$ for $5 \mathrm{~min}$ and then phosphorylation of Akt and ERK1/2 was examined by Western blotting. 
Figure 3: Insulin promotes MIDN expression via PI3-kinase and ERK1/2 in SH-SY5Y cells.

(A) SH-SY5Y cells were pre-incubated with or without U0126 (U, $30 \mu \mathrm{M})$ or wortmannin (Wort, $500 \mathrm{nM}$ ) for $30 \mathrm{~min}$, then stimulated with insulin $(1 \mu \mathrm{M})$ for $2 \mathrm{~h}$. Expression levels of $M I D N$ were examined by RT-qPCR. Insulin significantly promoted $M I D N$ expression $\left({ }^{*} p<0.05\right)$, which was significantly blocked by U0126 and wortmannin (n=3-6, ${ }^{\#} p<0.05$ ). (B) SH-SY5Y cells were pre-incubated with or without $\mathrm{U} 0126(\mathrm{U}, 30 \mu \mathrm{M}$ ) or wortmannin (Wort, $500 \mathrm{nM}$ ) for 30 min, then stimulated with insulin $(1 \mu \mathrm{M})$ for $2 \mathrm{~h}$. Phosphorylation of Akt and ERK1/2 was examined by Western blotting.

Figure 4: Insulin regulates $M I D N$ promoter activity between -150 and -50 bp upstream of the transcription start site. (A) SH-SY5Y cells were transfected with different length MIDN promoters $(-600,-450,-300,-150,-100$ or -50 to +125 bp) linked to luciferase in a promoter-less plasmid (pGL3) and MIDN promoter activity was examined by measuring luciferase activity. MIDN promoter activity of the $-100 \sim+125$ bp fragment was significantly enhanced compared with that of the $-150 \sim+125$ bp fragment $(n=6, * p<0.05)$. The activity of the $-50 \sim+125 \mathrm{bp}$ fragment was significantly reduced compared with that of the $-100 \sim+125 \mathrm{bp}$ fragment $(\mathrm{n}=6, \stackrel{*}{p}<<0.05)$. (B) SH-SY5Y cells were transfected with different length MIDN promoters $(-150,-100$ or -50 to $+125 \mathrm{bp})$ linked to luciferase in a promoter-less plasmid (pGL3) and stimulated with insulin $(1 \mu \mathrm{M})$. MIDN promoter activity was examined by measuring luciferase activity. MIDN promoter activity of the $-100 \sim+125$ bp fragment was significantly enhanced compared with that of the $-150 \sim+125$ bp fragment $(n=3, * p<0.05)$ and the activity of the $-50 \sim+125 \mathrm{bp}$ fragment was significantly reduced compared with that of the $-100 \sim+125 \mathrm{bp}$ fragment $(\mathrm{n}=3, \stackrel{\#}{p}<0.05)$ in both the presence and absence of insulin.

Figure 5: cis-elements for TFAP2, AP-1 and CREB/ATF are involved in basal and 
insulin-induced MIDN expression. (A) Depiction of mutated sites in the MIDN promoter between -150 and $-50 \mathrm{bp}$. Putative binding sequences for various transcription factors were mutated as indicated (Mut 1-5). (B) SH-SY5Y cells were transfected with wild-type or mutated (Mut 1-4) MIDN promoter (-150 +125 bp) linked to luciferase in a promoter-less plasmid (pGL3), and stimulated with insulin $(1 \mu \mathrm{M}) . M I D N$ promoter activity was examined by measuring luciferase activity. The mutated $M I D N$ promoter activity was significantly enhanced compared with the wild-type promoter activity in both the presence and absence of insulin $(n=3$, ${ }^{*}{ }^{\#} p<0.05$ ). (C) SH-SY5Y cells were transfected with wild-type or mutated (Mut 5) MIDN promoter $(-100$ or $-50 \sim+125 \mathrm{bp})$ linked to luciferase in a promoter-less plasmid (pGL3), and stimulated with insulin $(1 \mu \mathrm{M}) . M I D N$ promoter activity was examined by measuring luciferase activity. The activity of $M I D N$ promoter (Mut 5 and $-50 \sim+125$ bp) was significantly reduced compared with the wild-type promoter activity $(-100 \sim+125 \mathrm{bp})$ in both the presence and absence of insulin $\left(\mathrm{n}=6,{ }^{*},{ }^{*} p<0.05\right)$.

Figure 6: A dominant-negative TFAP2B mutant enhanced $M I D N$ promoter activity in SH-SY5Y cells. (A) SH-SY5Y cells were co-transfected with wild-type MIDN promoter $(-150 \sim+125 \mathrm{bp})$ linked to luciferase in a promoter-less plasmid (pGL3) and empty vector (pcDNA3.1), wild-type TFAP2B (WT) or a dominant-negative TFAP2B mutant (R225C). MIDN promoter activity was examined by measuring luciferase activity. MIDN promoter activity was significantly enhanced by overexpression of TFAP2B R225C ( $\left.\mathrm{n}=6,{ }^{*} p<0.05\right)$. (B) SH-SY5Y cells were co-transfected with reporter plasmids and TFAP2B WT or its dominant-negative mutant as described above, and overexpression of TFAP2B and TFAP2B-R225C was examined by Western blotting.

Figure 7: CREB is not involved in MIDN promoter activation by insulin in SH-SY5Y cells.

(A) SH-SY5Y cells were preincubated in the presence or absence of U0126 (U, $30 \mu \mathrm{M})$ or 
wortmannin (Wort, $500 \mathrm{nM}$ ) for $30 \mathrm{~min}$ and then stimulated with insulin $(1 \mu \mathrm{M})$ for $2 \mathrm{~h}$. Phosphorylation of CREB was examined by Western blotting. (B) SH-SY5Y cells were cotransfected with wildtype MIDN promoter $(-100 \sim+125$ bp) linked to luciferase in a promoter-less plasmid (pGL3) and empty vector (pcDNA3.1), wildtype CREB (WT) or a dominant-negative CREB mutant (S133A) and then stimulated with insulin $(1 \mu \mathrm{M})$. MIDN promoter activity was examined by measuring luciferase activity. MIDN promoter activity was significantly enhanced by overexpression of CREB WT and the S133A mutant ( $\left.\mathrm{n}=3,{ }^{*}{ }^{*} p<0.05\right)$.

Figure 8: Insulin promotes $c-F O S$ expression and AP-1 is involved in $M I D N$ promoter activation by insulin in SH-SY5Y cells. (A) SH-SY5Y cells were pre-incubated in the presence or absence of $\mathrm{U} 0126(\mathrm{U}, 30 \mu \mathrm{M})$ or wortmannin (Wort, $500 \mathrm{nM}$ ) for $30 \mathrm{~min}$, then stimulated with insulin $(1 \mu \mathrm{M})$ for $2 \mathrm{~h}$. Gene expression levels of $c-F O S$ were examined by RT-qPCR. Insulin significantly promoted $c-F O S$ expression $\left(\mathrm{n}=3-6,{ }^{*} p<0.05\right)$, which was significantly blocked by U0126 ( $\mathrm{n}=3-6,{ }^{*} p<0.05$ ). (B) SH-SY5Y cells were pre-incubated in the presence or absence of $\mathrm{U} 0126(\mathrm{U}, 30 \mu \mathrm{M})$ or wortmannin (Wort, $500 \mathrm{nM}$ ) for $30 \mathrm{~min}$, then stimulated with insulin $(1 \mu \mathrm{M})$ for $2 \mathrm{~h}$. c-FOS and GAPDH levels were examined by Western blotting. (C) SH-SY5Y cells were cotransfected with wildtype MIDN promoter (-100 +125 bp) linked to luciferase in a promoter-less plasmid (pGL3) and scrambled or decoy ODNs $(2 \mu \mathrm{g})$ and then stimulated with insulin $(1 \mu \mathrm{M}) . M I D N$ promoter activity was examined by measuring luciferase activity. Insulin significantly promoted $M I D N$ promoter activity $\left(\mathrm{n}=6,{ }^{*} p<0.05\right)$, which was significantly blocked by the decoy ODN ( $\left.n=6,{ }^{*} p<0.05\right)$. (D) SH-SY5Y cells were transfected with the wildtype $M I D N$ promoter $(-100 \sim+125 \mathrm{bp})$ linked to luciferase in a promoter-less plasmid (pGL3). The cells were preincubated with or without SR11302 (10-30 $\mu \mathrm{M})$ and then stimulated with insulin $(1 \mu \mathrm{M})$. MIDN promoter activity was examined by measuring luciferase activity. Insulin significantly promoted $M I D N$ promoter activity $(\mathrm{n}=4-8$, 
$\left.{ }^{*} p<0.05\right)$, which was significantly blocked by SR11302 ( $\left.\mathrm{n}=4-8,{ }^{*} p<0.05\right)$. (E) SH-SY5Y cells were stimulated with insulin $(1 \mu \mathrm{M})$ for $2 \mathrm{~h}$. Then, ChIP assays were performed using control IgG, c-JUN, and c-FOS antibodies. The MIDN promoter region (-185 to $+7 \mathrm{bp})$, which included the predicted AP-1 consensus sequence ( -71 to $-57 \mathrm{bp})$, and intron $1(+840$ to $+969 \mathrm{bp})$ was amplified by qPCR. Insulin significantly promoted DNA binding of both c-JUN and c-FOS to the $M I D N$ promoter region $\left(\mathrm{n}=3,{ }^{*} p<0.05\right)$.

Figure 9: A putative insulin signalling pathway for promoting $M I D N$ expression. Insulin upregulates $M I D N$ expression accompanied by the activation of ERK1/2 and PI3-kinase pathways. It is assumed that AP-1 rather than CREB promotes MIDN expression downstream of ERK1/2 and PI3-kinase pathways, whereas TFAP2 suppresses MIDN expression. 
(A)

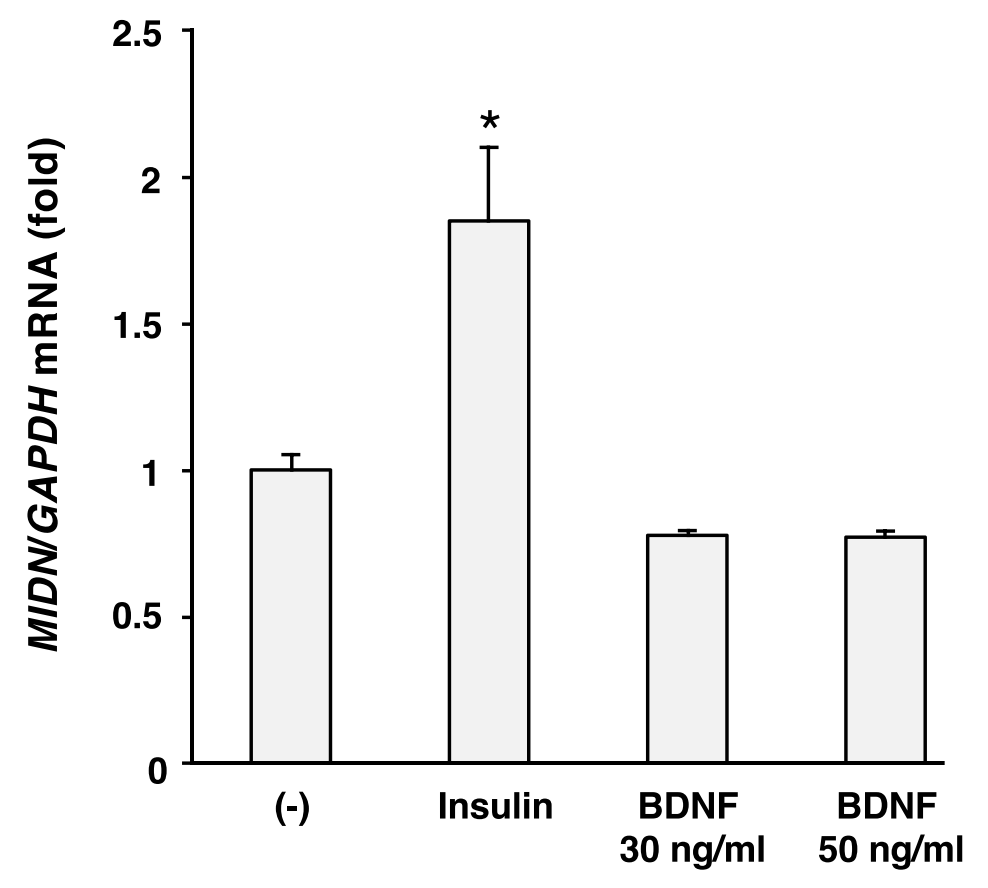

(C)

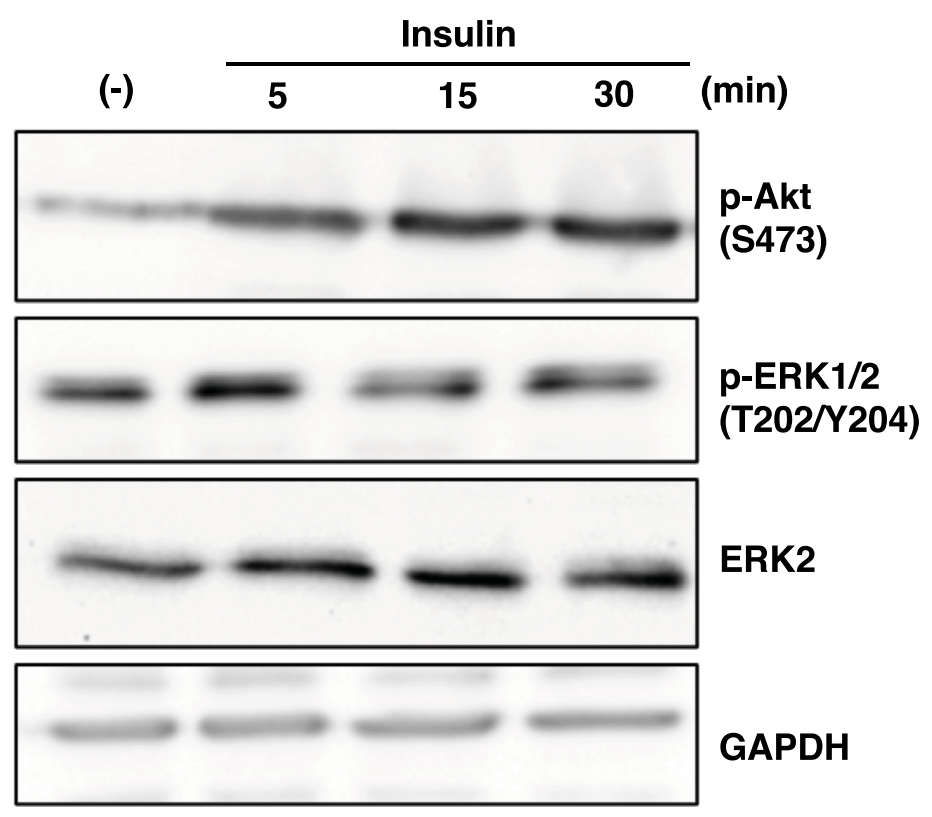

(B)

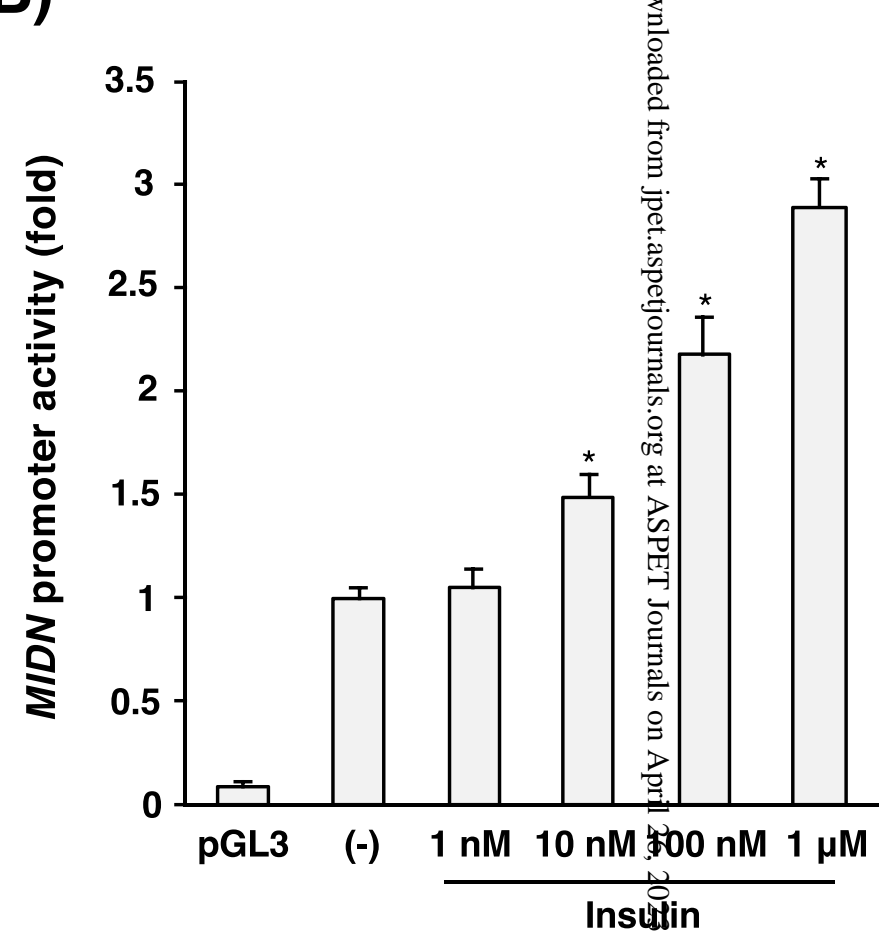

(D)

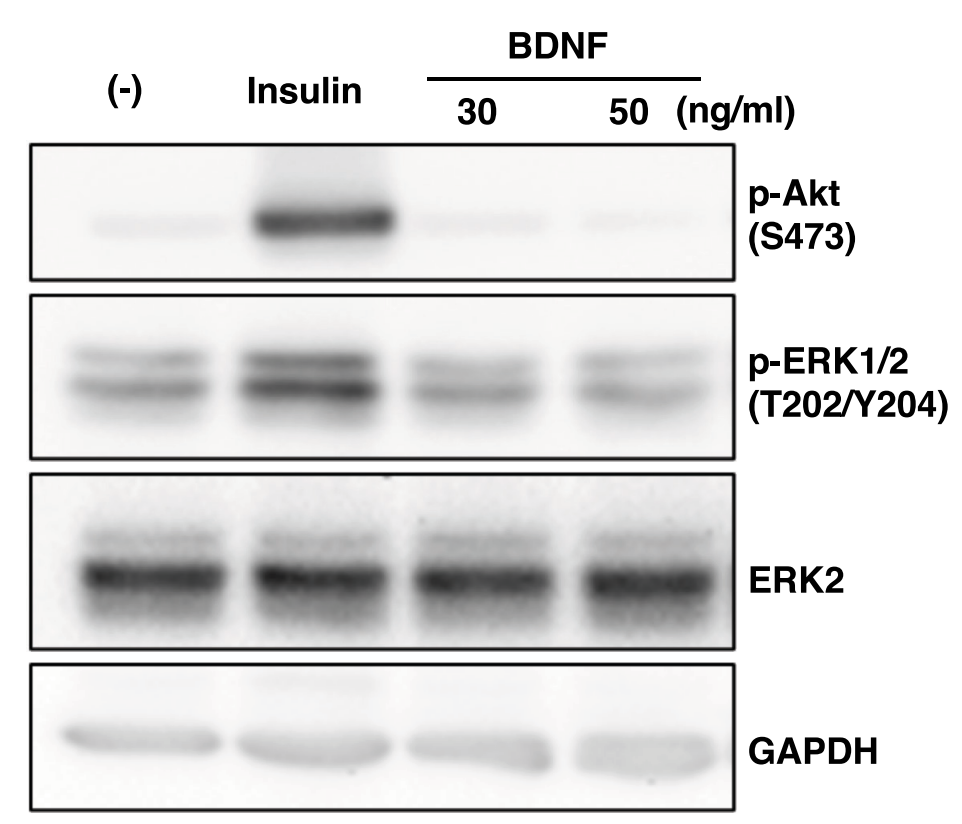

Fig. 1 
(A)

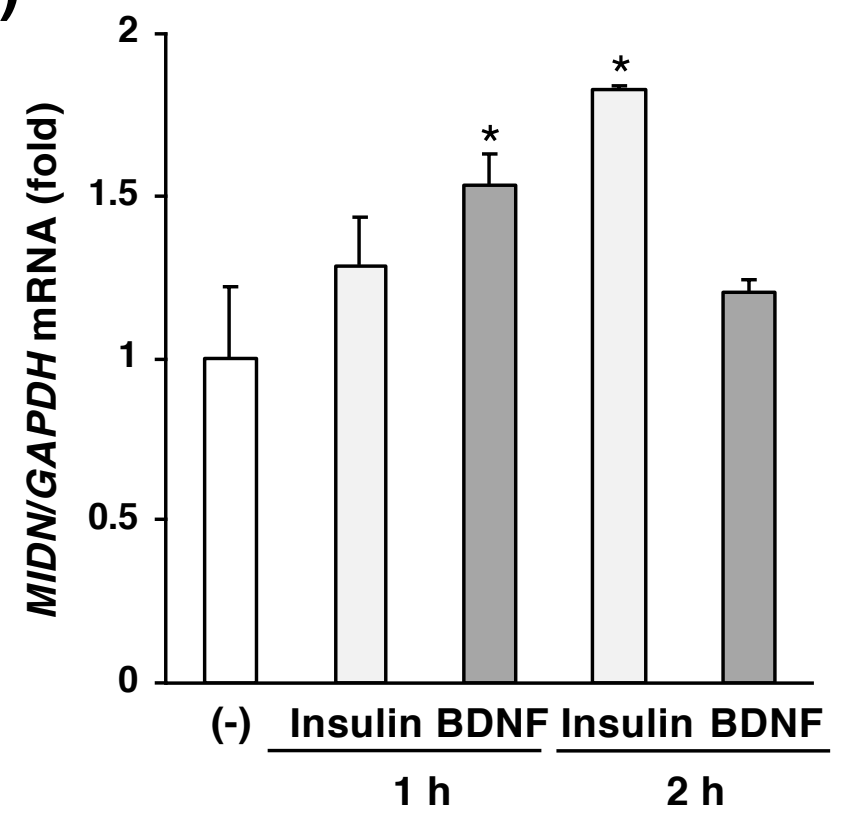

(C)

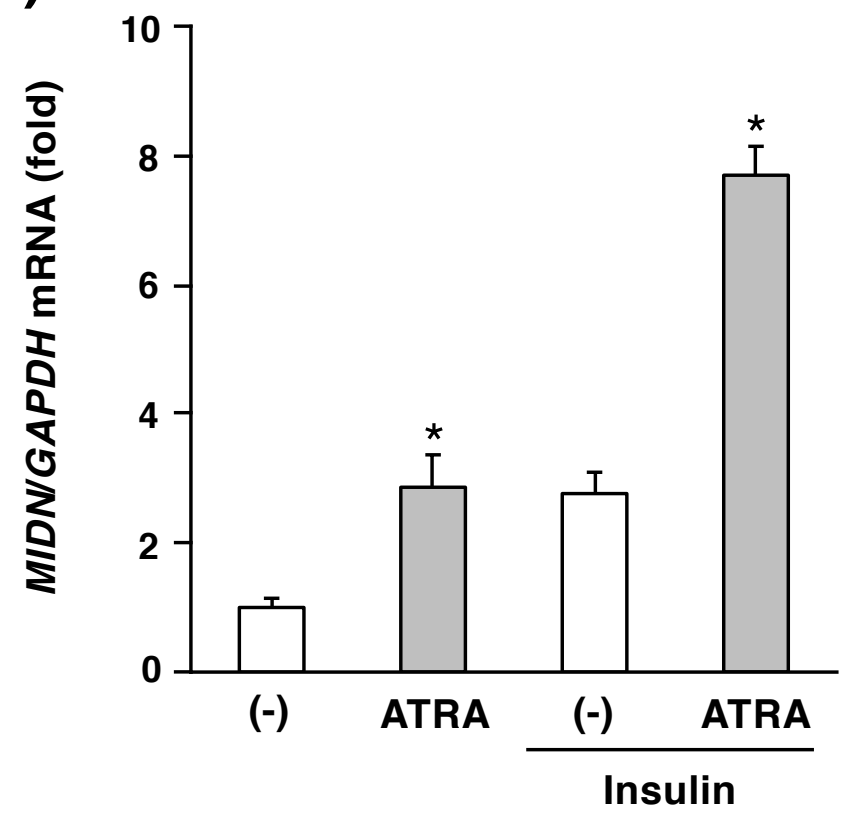

(B)

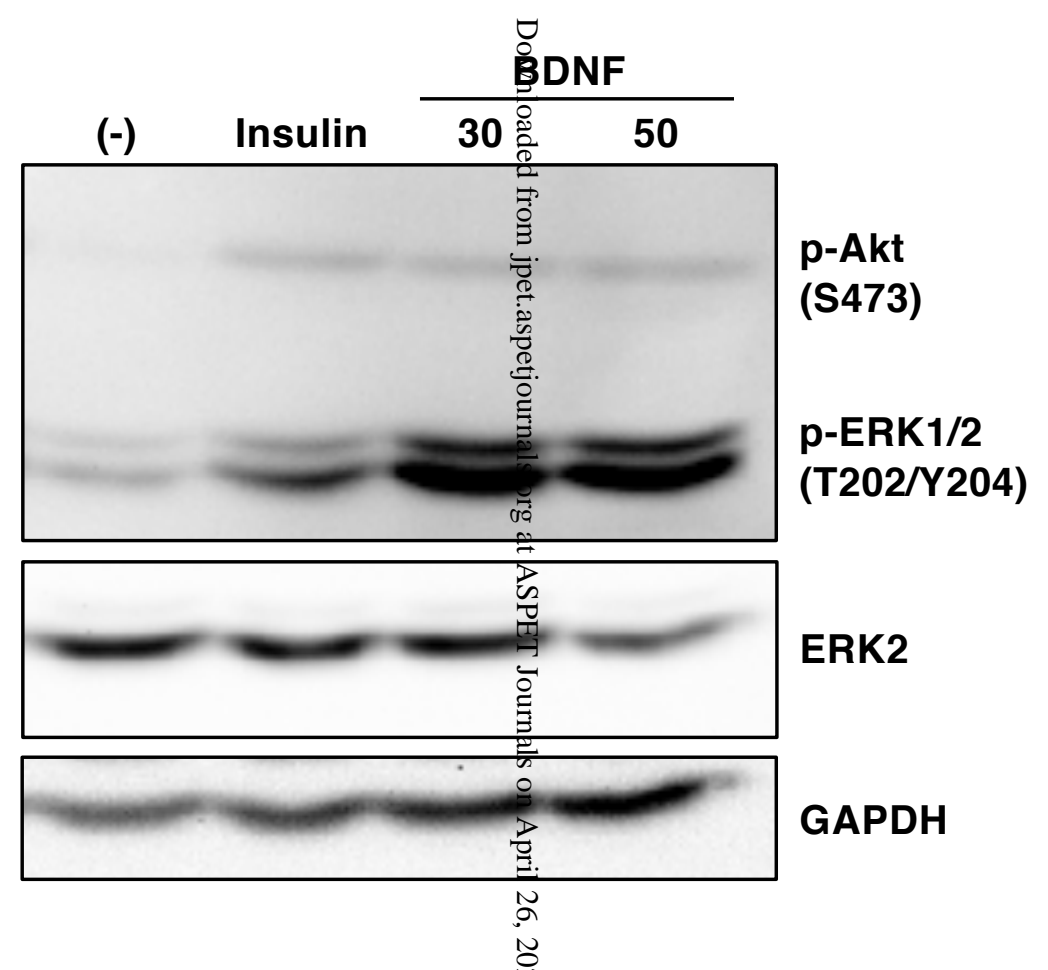

(D)

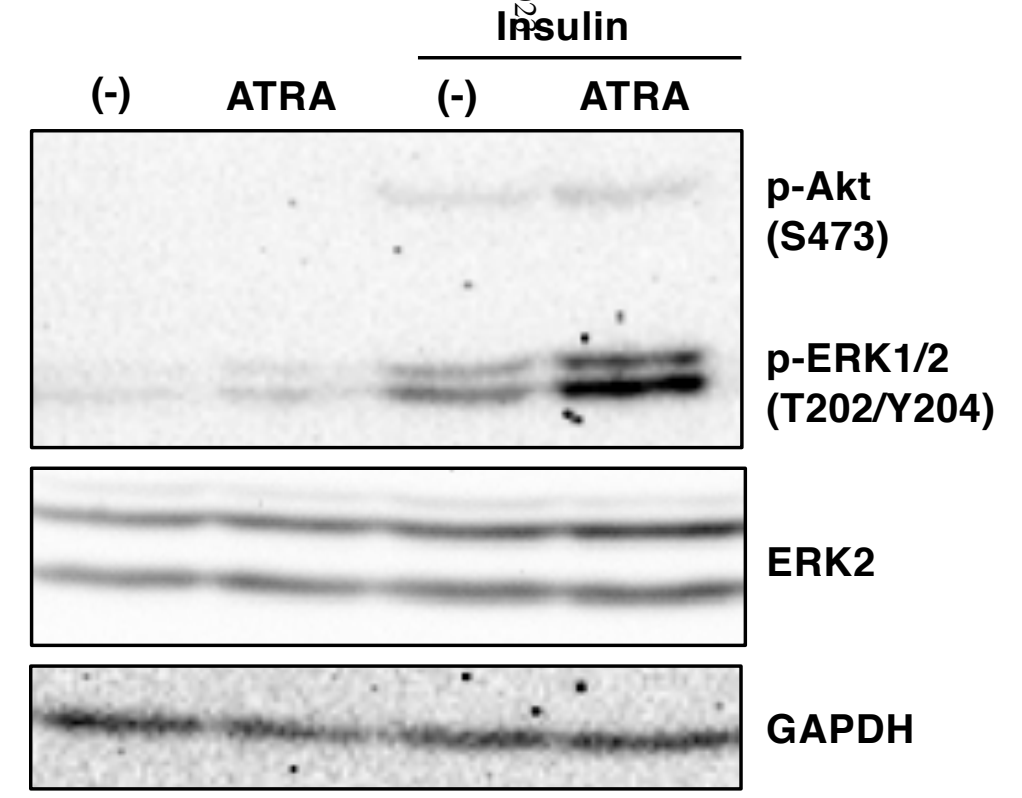

Fig. 2 
(A)

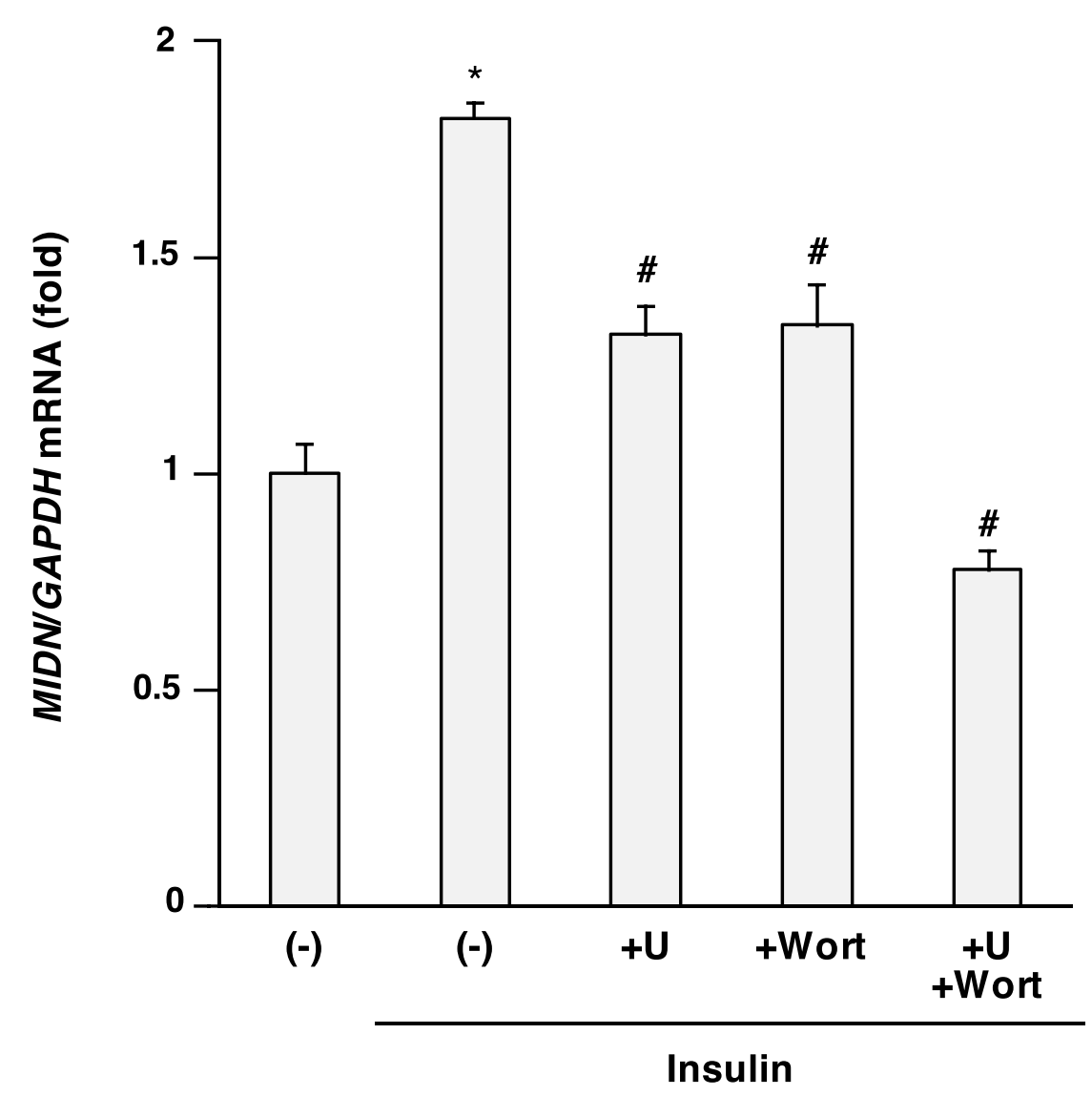

(B)
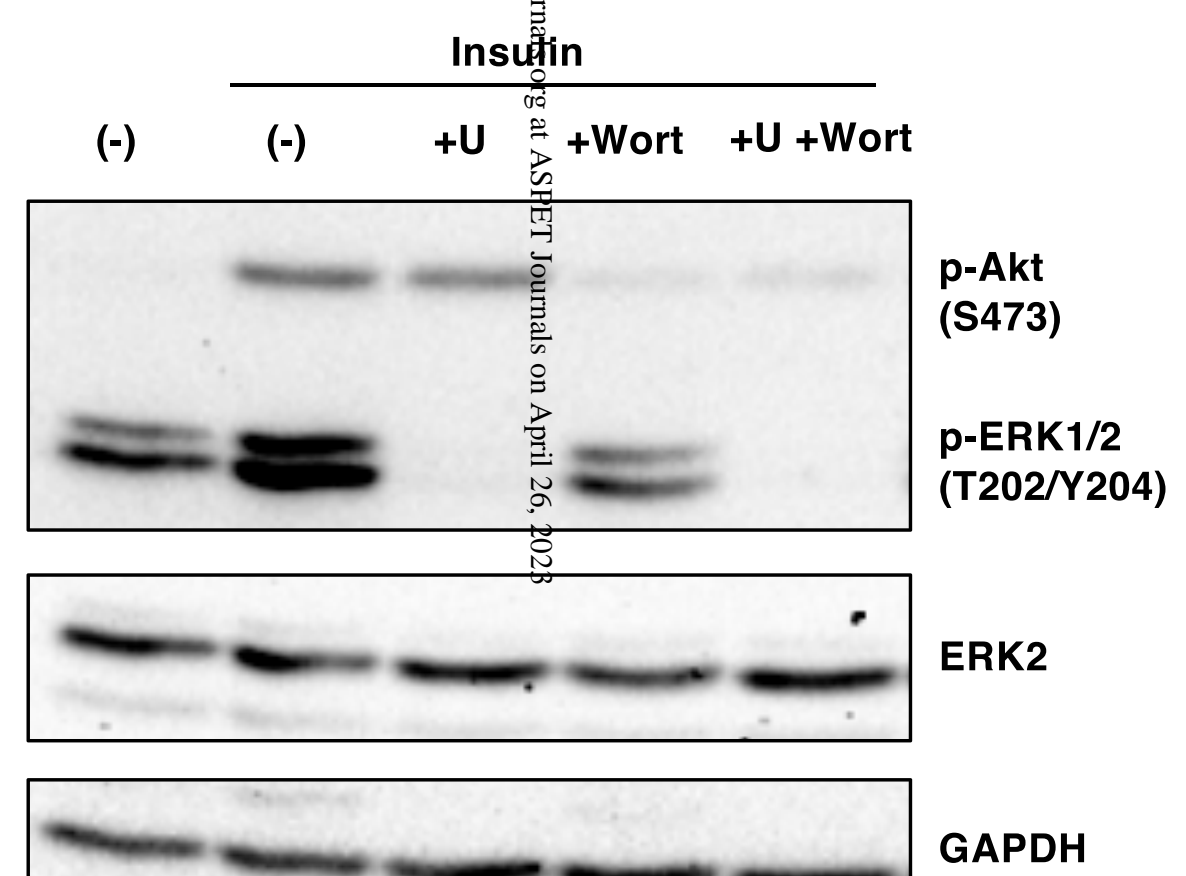

Fig. 3 
(A)

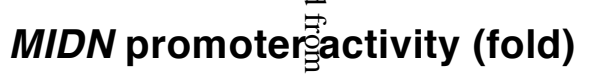

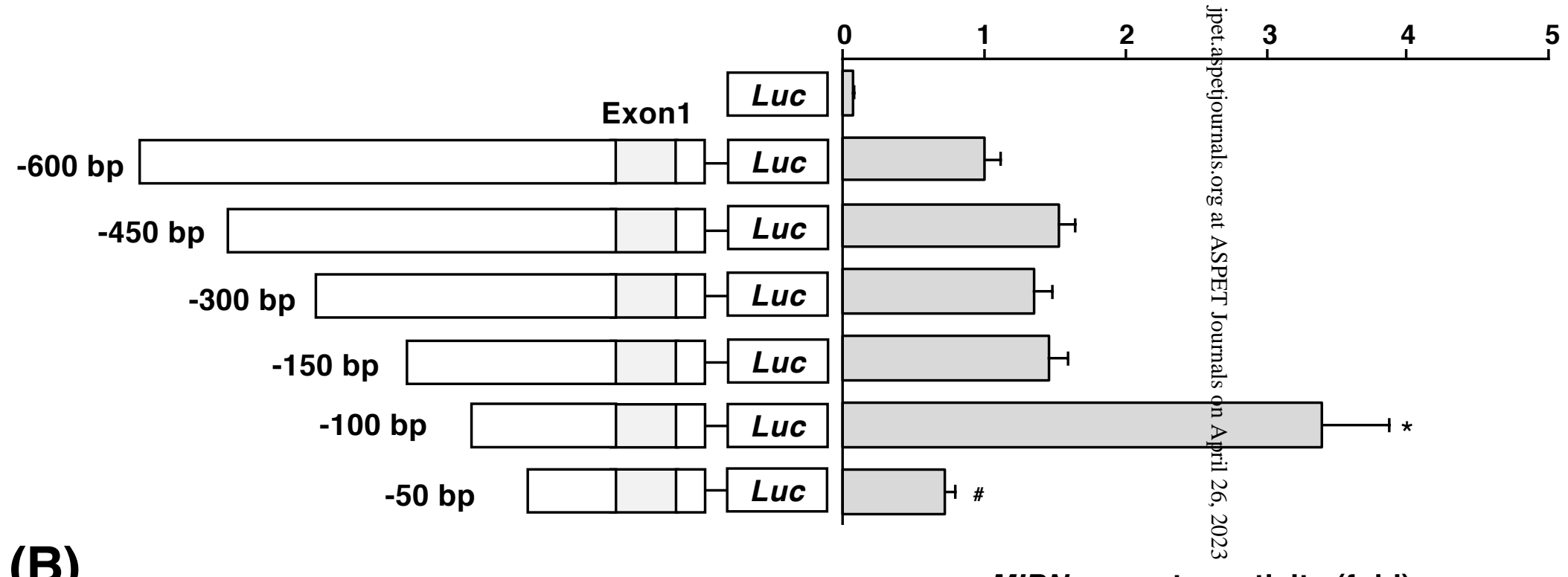

(B)

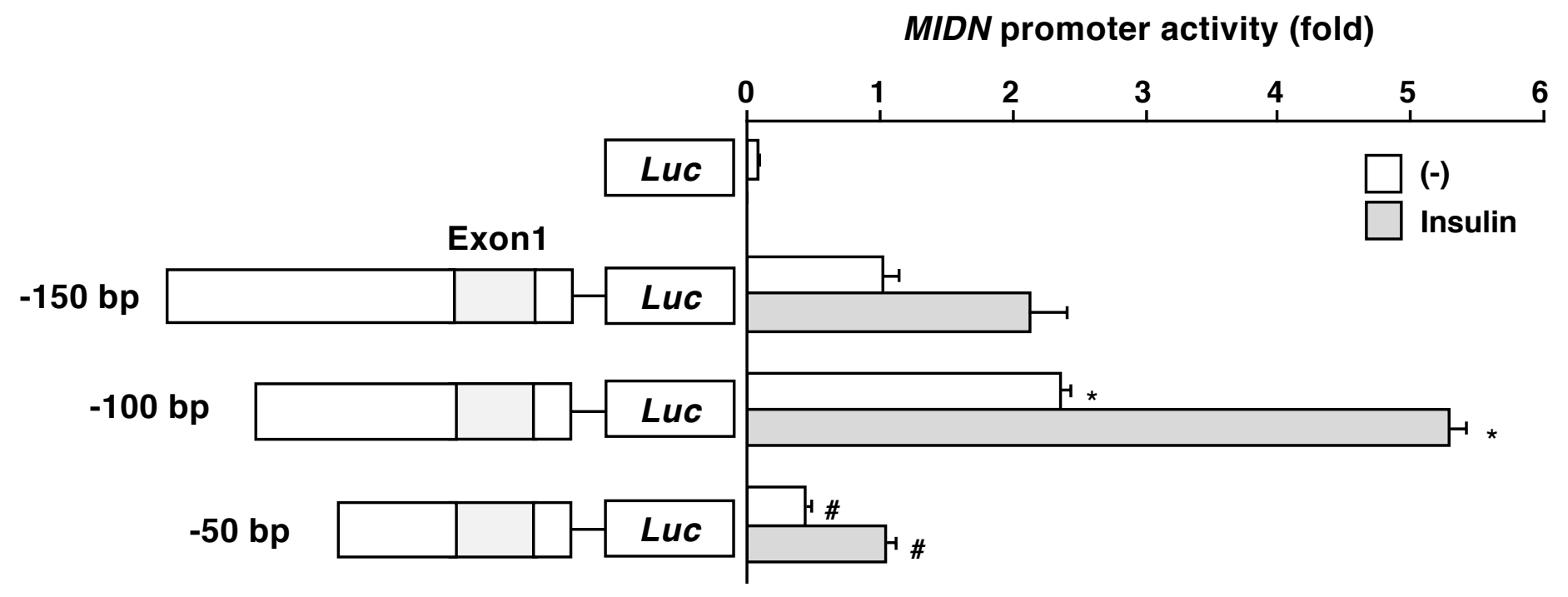

Fig. 4 
(A)

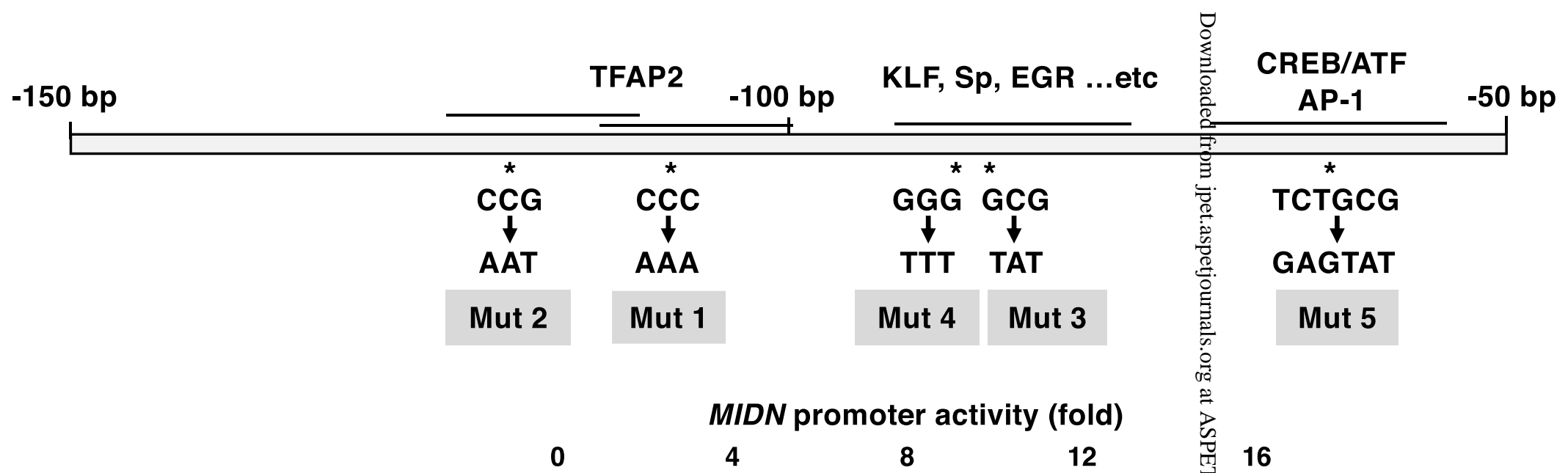

(B)

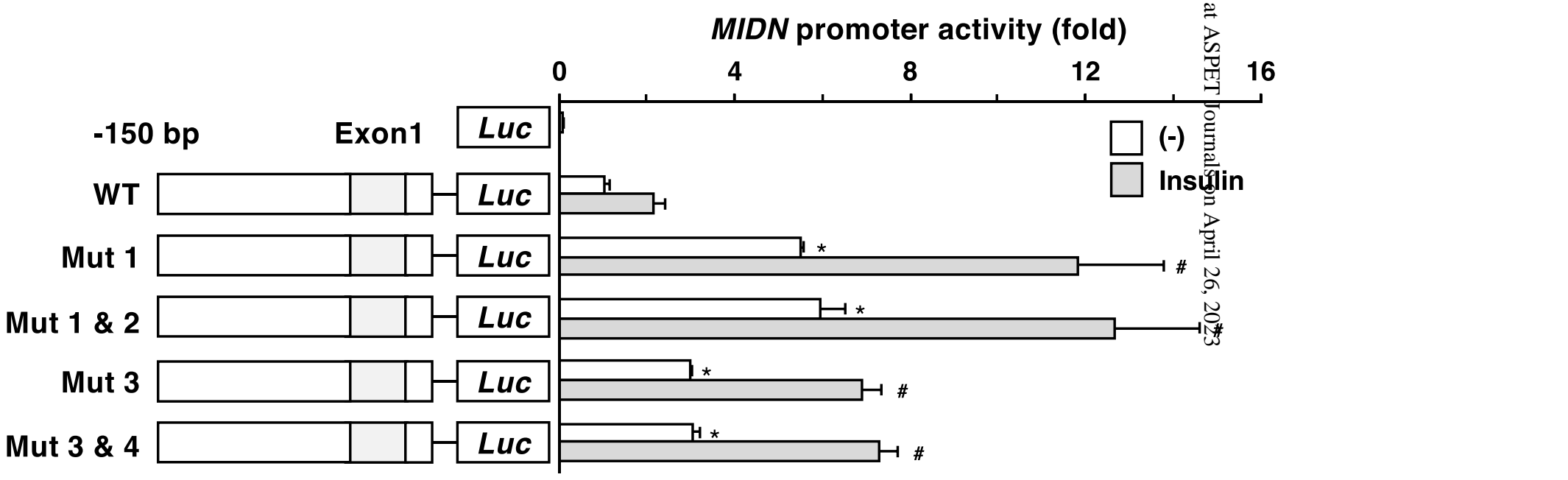

(C)

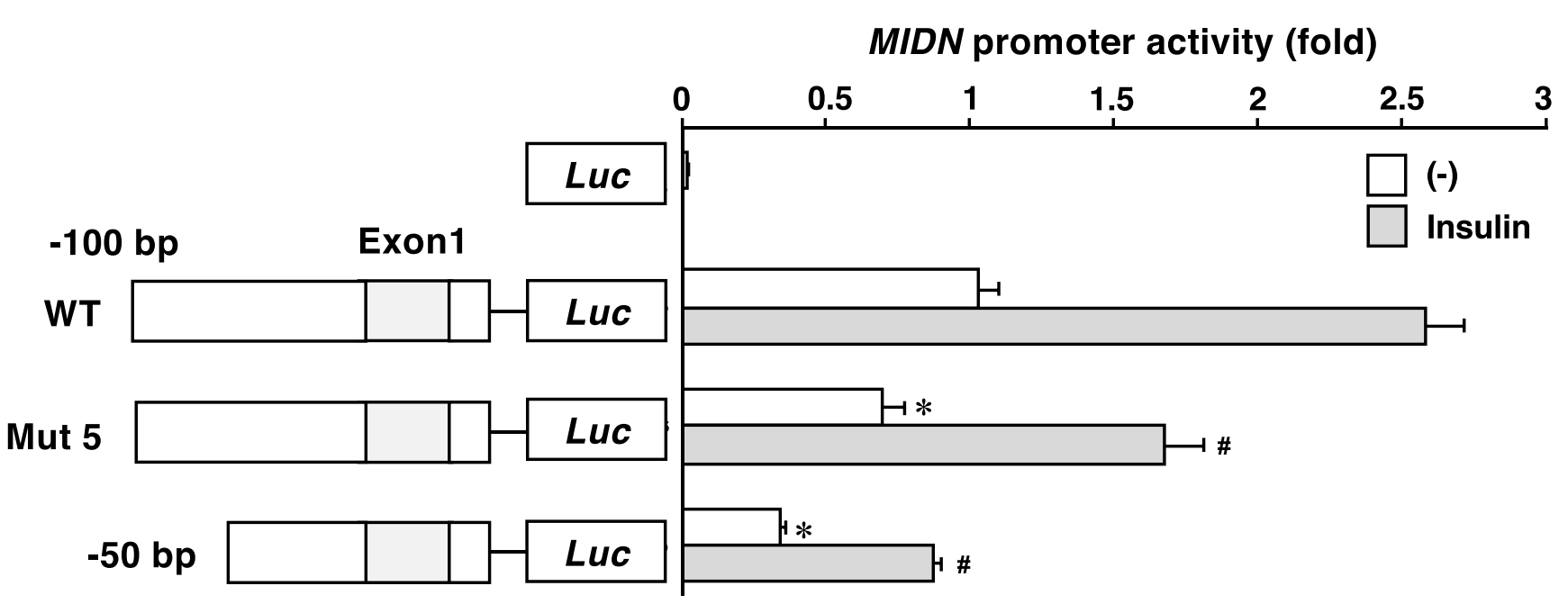

Fig. 5 
(A)

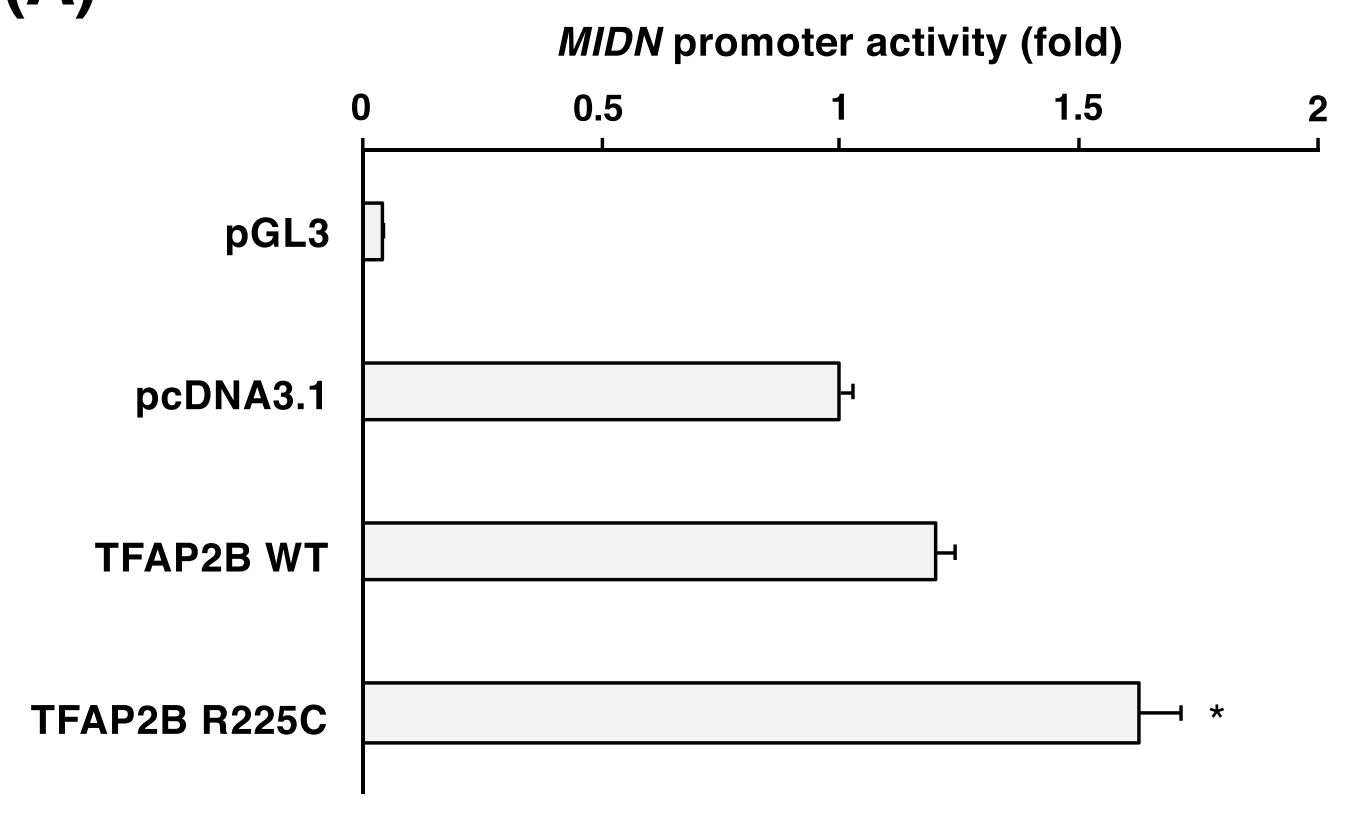

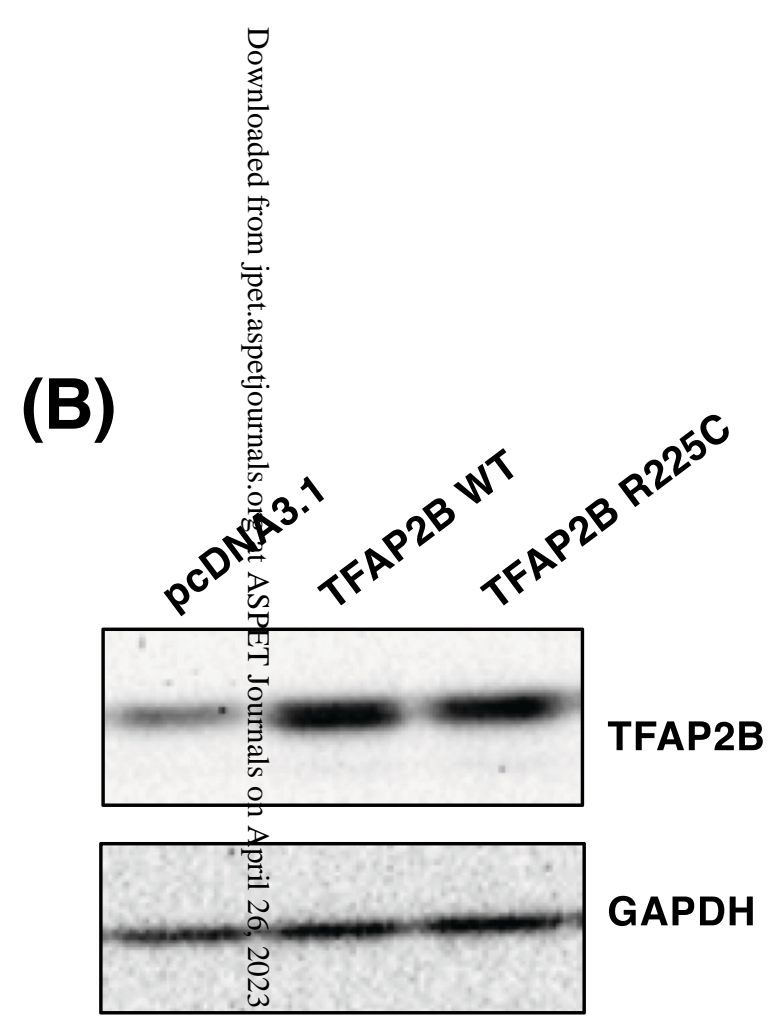

Fig. 6 
(A)
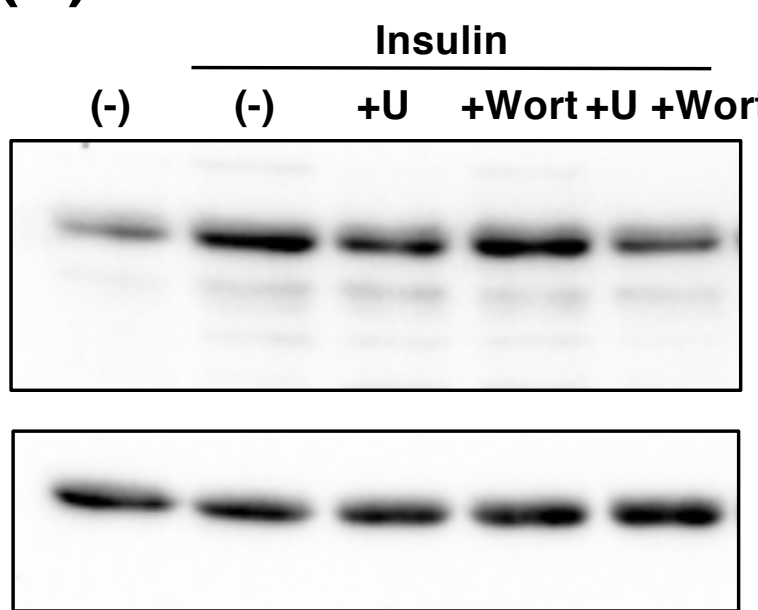

(B)

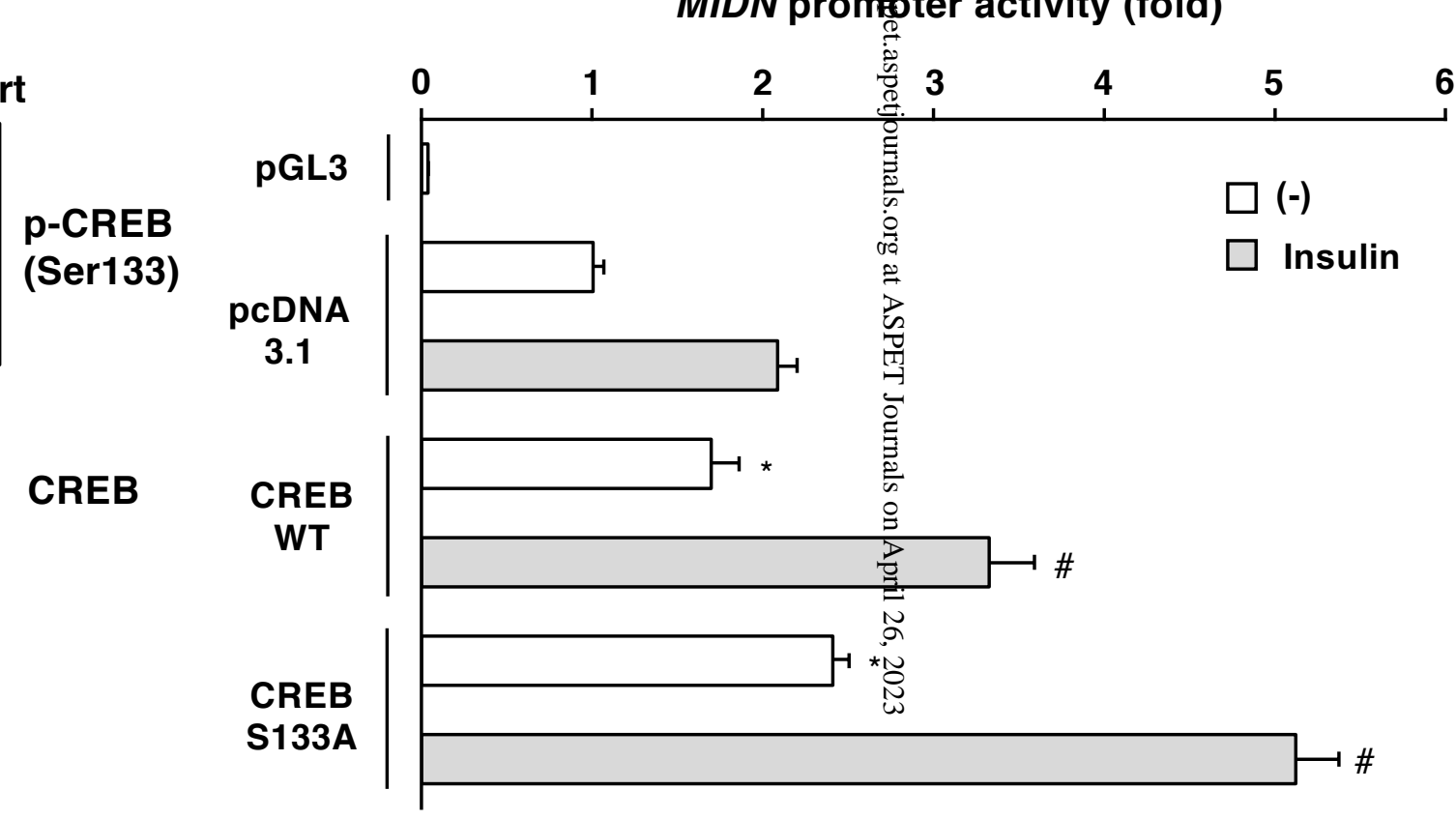

Fig. 7 


\section{(A)}

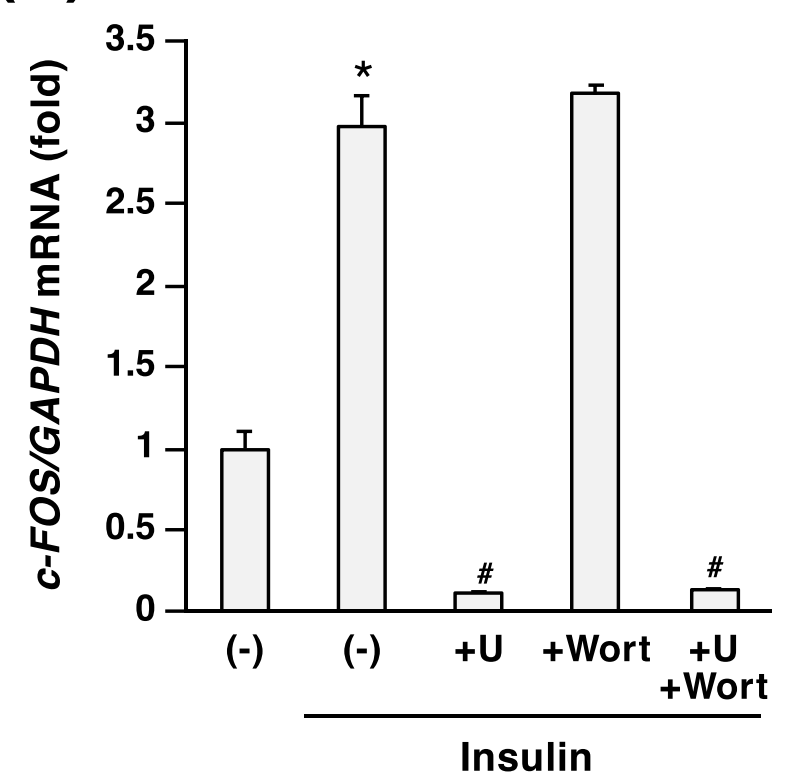

(D)

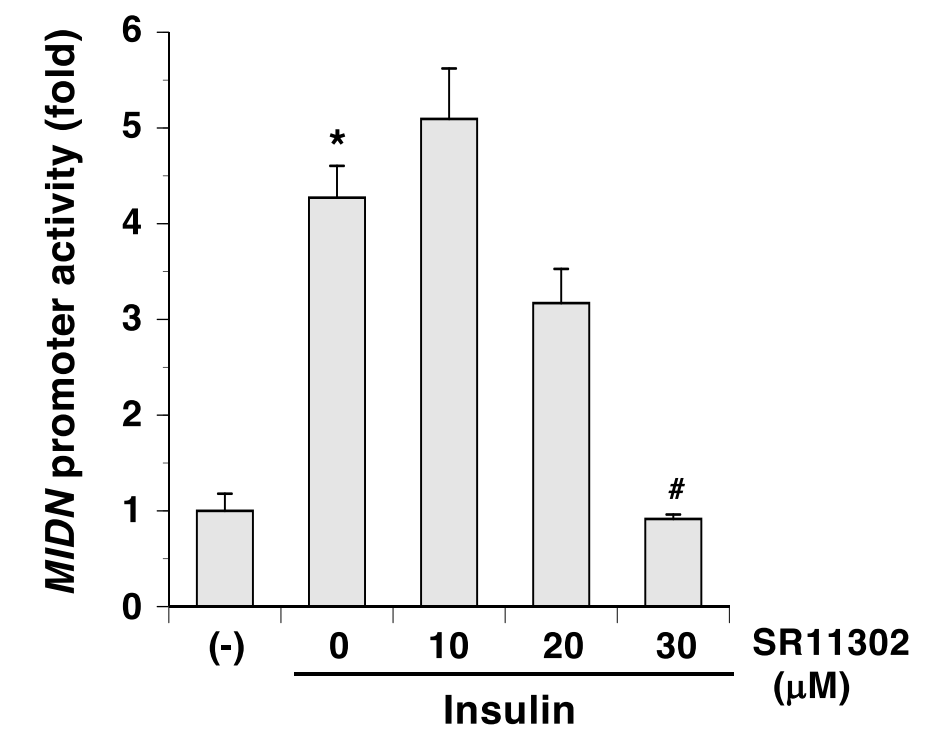

(B)

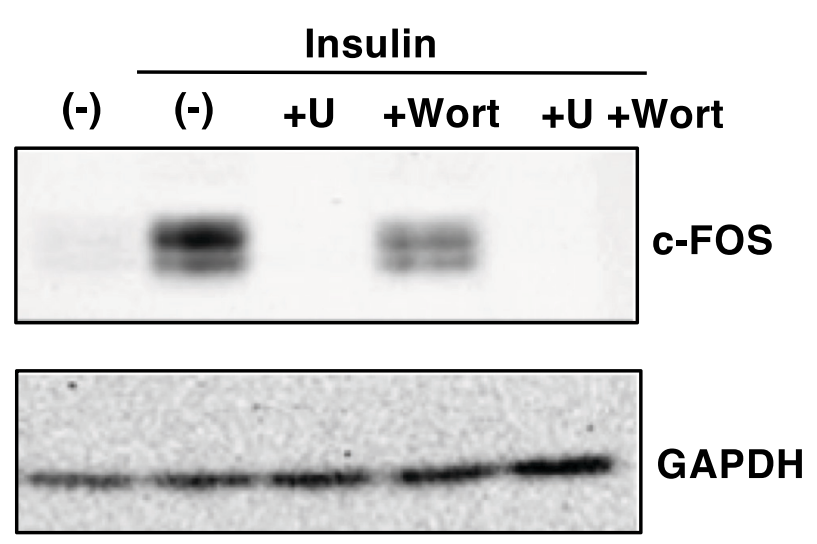

(E)

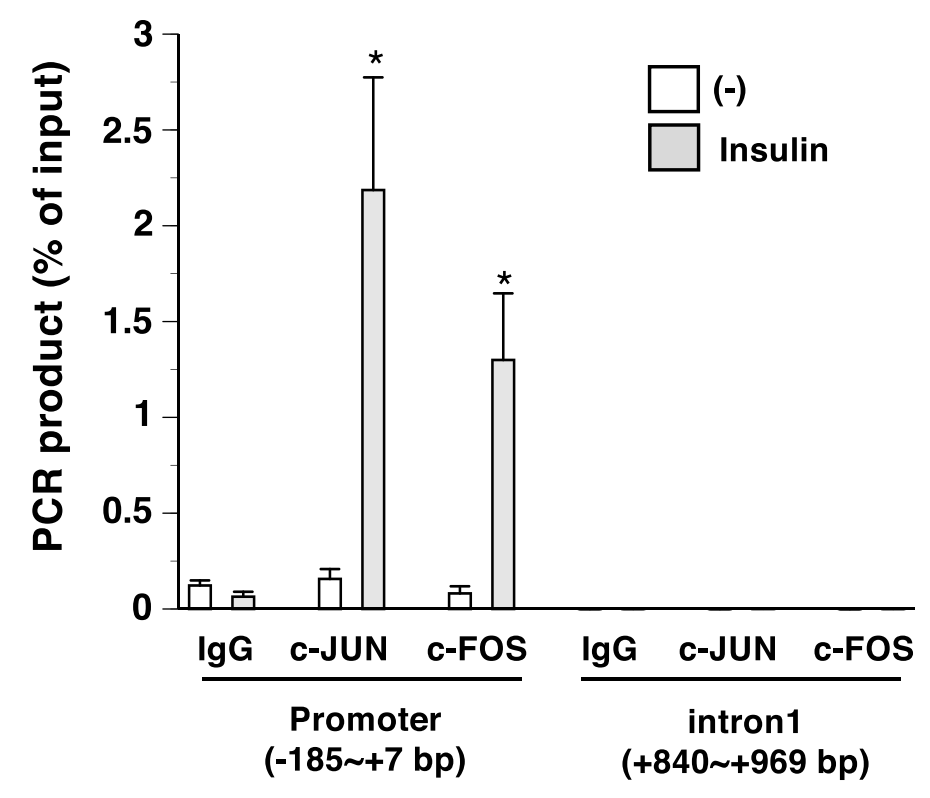

(C)

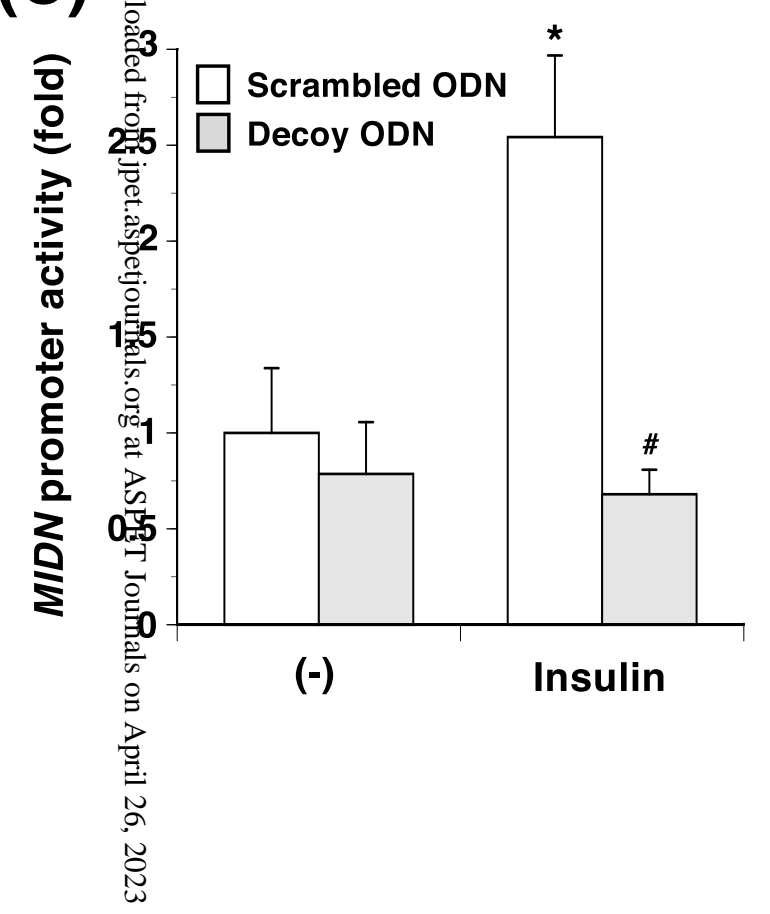

sulin

Fig. 8 


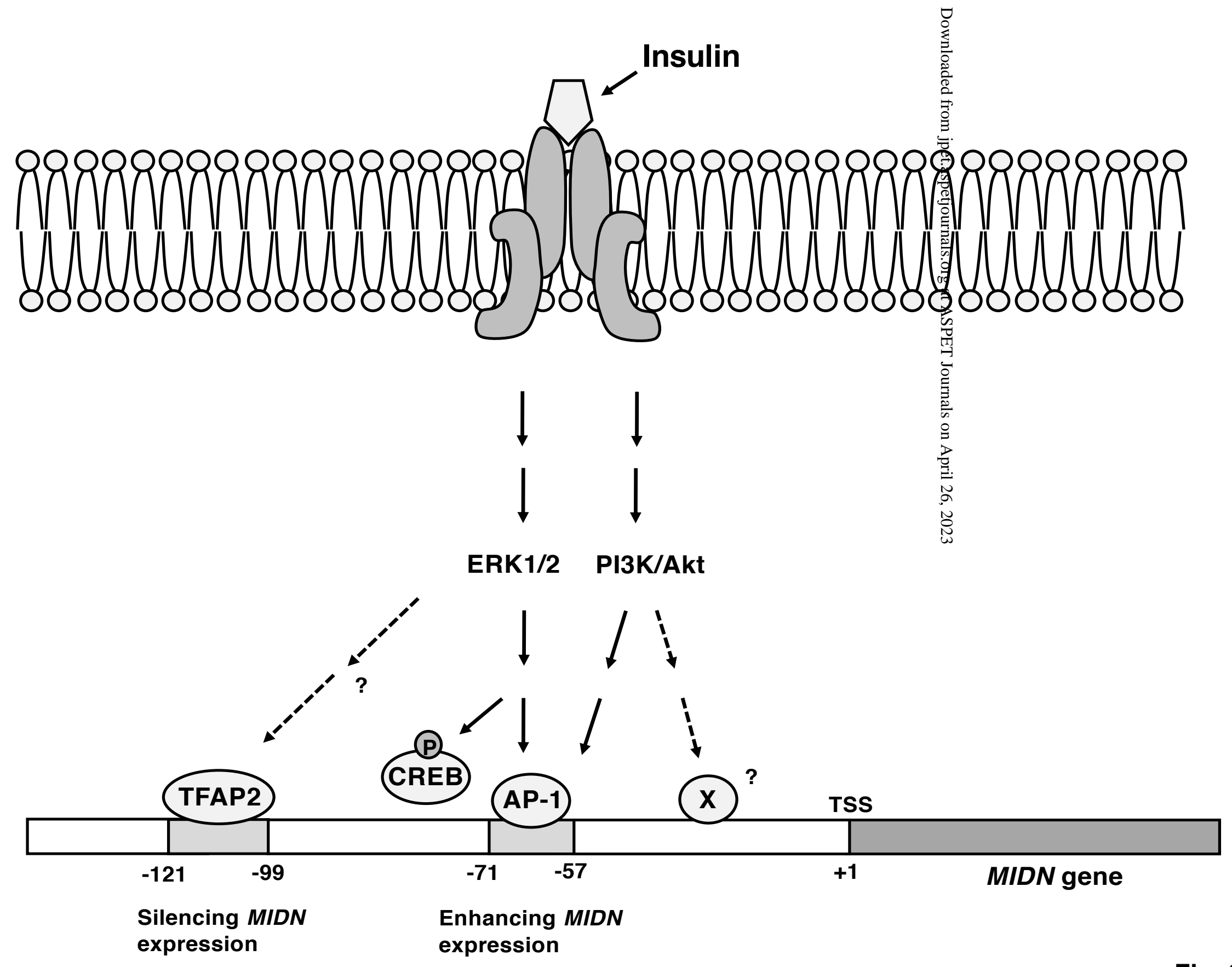

Fig. 9 